Revista Universo Contábil, ISSN 1809-3337

Blumenau, v. 11, n. 1, p. 105-135, jan./mar., 2015

doi:10.4270/ruc.2015106

Disponível em www.furb.br/universocontabil

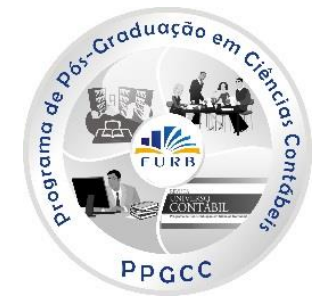

\title{
DIVERSIFICATION WITH THE OPTION-TO-ABANDON: AN INTEGRATED VALUATION MODEL1
}

\section{DIVERSIFICAÇÃO COM A OPÇÃO DE ABANDONO: UM MODELO DE AVALIAÇÃO INTEGRADO}

\section{LA DIVERSIFICACIÓN CON LA OPCIÓN DE ABANDONO: UN MODELO DE VALORACIÓN INTEGRADA}

Carlos A. De Mello-e-Souza

$\mathrm{PhD}$ in Accounting - Cornell University Associate Professor - Albers School of Business and Economics Address: Seattle University, 901 - 12th Avenue, Seattle, WA 98122

E-mail:carlosms@seattleu.edu

\begin{abstract}
A model that recognizes the possibility of total shareholder loss in the aftermath of bankruptcy reveals simultaneously the stock price effects of diversification and of the option to abandon assets to creditors. In essence the model integrates security pricing behavior predicted by the CAPM and by the OPM in a single formula. Results have implications for the valuation of equity and debt securities of firms in distress and of options when underlying cash flows are correlated with the market. The analysis suggests why models that consider only diversification or the option-to-abandon sometimes fail to track the behavior of actual returns.
\end{abstract}

Keywords: Asset Pricing, Bankruptcy, Limited Liability, OPM, Option Pricing, Systematic Risk.

\section{RESUMO}

Um modelo que reconhece a possibilidade de perda total para o acionista no rescaldo da falência revela simultaneamente os efeitos de preço das ações de diversificação e da opção de abandonar ativos aos credores. Em essência, o modelo integra o comportamento de precificação previsto pelo CAPM e pela OPM em uma única fórmula. Os resultados têm implicações para a avaliação do patrimônio líquido e da dívida de empresas em dificuldades $e$ de opções quando os fluxos de caixa subjacentes são correlacionados com o mercado. A análise sugere porque os modelos que consideram apenas a diversificação ou a opção de abandono, por vezes, não conseguem acompanhar o comportamento dos retornos reais.

\footnotetext{
1 Artigo recebido em 09.09.2014. Recomendado para publicação em 31.12.2014 por Ilse Maria Beuren. Publicado em 31.03.2015. Organização responsável pelo periódico: FURB.
} 
Palavras-chave: Precificação de Ativos, Falência, Responsabilidade Limitada, OPM, Precificação de Opções, Risco Sistemático.

\section{RESUMEN}

Un modelo que reconoce la posibilidad de la pérdida total de los accionistas en las consecuencias de la quiebra revela simultáneamente los efectos de precios de acciones de diversificación y de la opción de abandonar los activos a los acreedores. En esencia, el modelo integra la política de valoración previsto por el CAPM y por la OPM en una sola fórmula. Resultados tienen implicaciones para la valoración del patrimonio neto y la deuda de empresas en dificultades y de opciones cuando los flujos de efectivo subyacentes están correlacionados con el mercado. El análisis sugiere por qué los modelos que tienen en cuenta sólo la diversificación o la opción de abandono a veces no puede seguir el comportamiento de los rendimientos reales.

Palabras clave: Valoración de Activos, Quiebra, Responsabilidad Limitada, OPM, Valoración de Opciones, Riesgo Sistemático.

\section{INTRODUCTION}

In this paper I am concerned with the impact of contagious bankruptcy risk (bankruptcy being defined as the prospect of shareholders losing their entire stake in a firm) on the valuation of common stock, and in particular with whether the introduction of bankruptcy risk allows combining the effects of diversification and of the option-to-abandon assets to creditors in a single valuation formula.

Contagious bankruptcy is interesting from the standpoint of security prices for two reasons. The first is that contagious bankruptcy risk cannot be diversified away, and therefore investors should demand - and in equilibrium receive-compensation for bearing it. The second reason is that, although risk of total loss is always present, its effects are insufficiently represented in historical stock return files (SHUMWAY, 1997). Consequently, conventional techniques for gauging the association between firm specific returns and market-wide returns may fail to account appropriately for the risk of total shareholder loss. If bankruptcy risk is not being measured and yet should be priced, valuations made by conventional techniques are incorrect. To the extent markets reject these valuations, predictions made by conventional techniques will fail to track real pricing behavior.

Average bankruptcy risk in the U.S. is not very large. Anticipating results obtained later in the paper, the aggregate risk of default (which is of course higher than risk of total loss) in the U.S. is too small to have a significant impact on security values. But this does not mean that risk of default is too small to matter for all firms. Default risk attains relatively high levels for a significant number of firms: $24 \%$ on average over the next twelve months for about one tenth of all firms rated by Moody's. (See Figure 1.)

I begin this study by obtaining expressions for systematic risk and expected returns that account for bankruptcy risk. With these expressions I examine the issue of combining the option-to-abandon and diversification effects by contrasting implications of the new valuation formula with those of the Black-Scholes (1973) option pricing model and with those of the capital asset pricing model (CAPM) as traditionally applied. The analysis is based on a prototypical firm that raises cash by issuing debt and equity and uses the proceeds to buy productive assets. The firm hopes to generate cash from operations and will be liquidated within one year by distributing all available cash to stakeholders. The basic requirement for embedding option-like behavior within the CAPM is to assume that in some states of the world cash flows will be inadequate to meet obligations to debtholders, and in those states shareholders will walk 
away from the firm. This is permissible in the context of the original Sharpe-Lintner-Mossin CAPM (MOSSIN, 1973) with quadratic utilities. ${ }^{1}$

Figure 1. Moody's global corporate bonds: 1-year default rate quartiles for 1970-2003 by risk class. Fraction of bonds by risk class is for 2003. (Moody's Investors Service.)

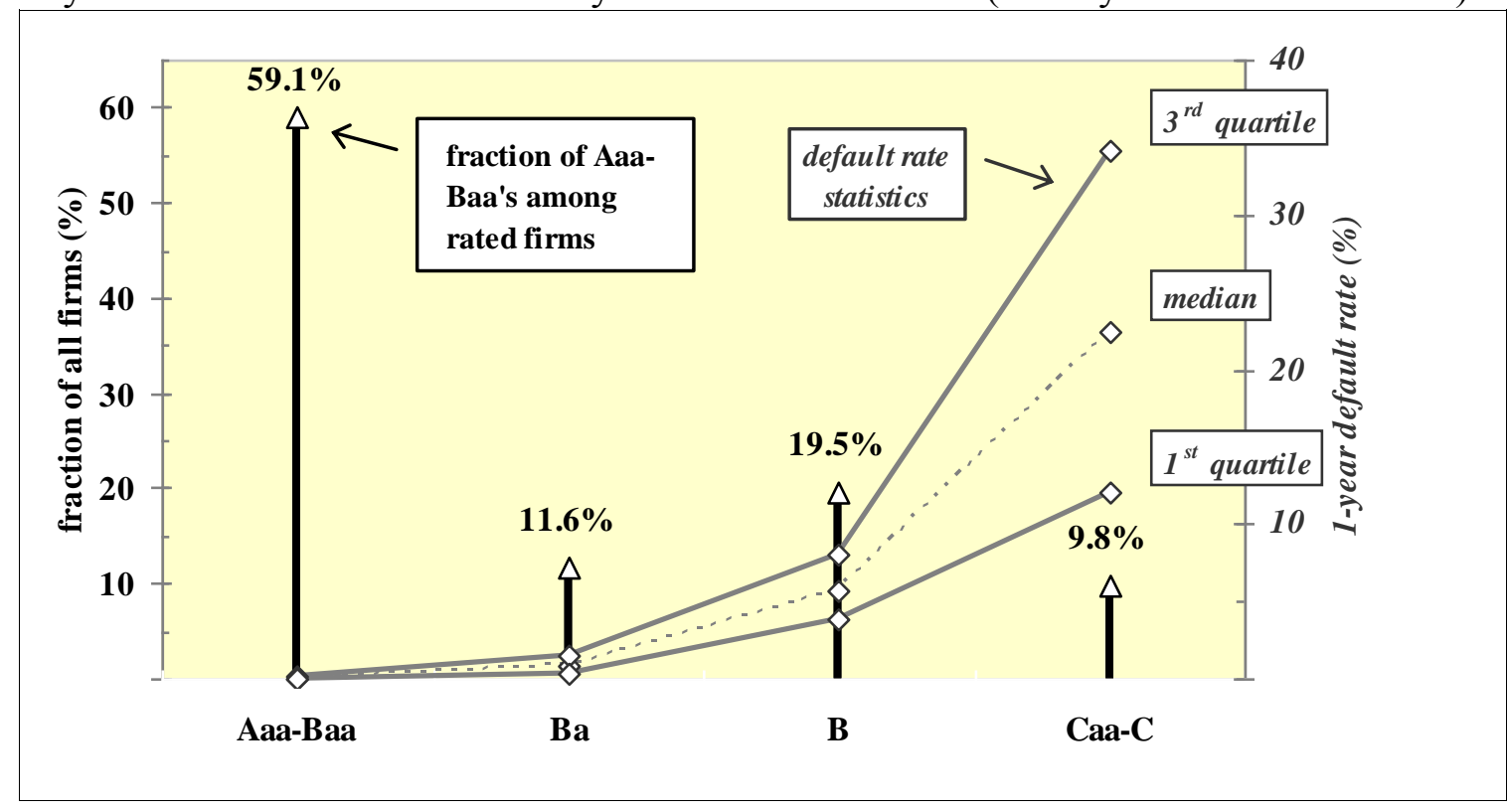

But another requirement for instilling option-like features in equilibrium prices is to face up to the fact that, given truncated returns, covariation between equity and market returns must be affected by bankruptcy risk as well as by the correlation of operating cash flows with the economy (MUTHÉN, 1990). The only question is how strong is the effect of total losses on that covariation and on systematic risk, not whether the effect exists. Procedures to estimate firm-to-market covariation that ignore bankruptcy risk lead to errors just like trying to estimate a linear regression ignoring that the dependent variable has limited range. This difficulty is not mitigated by the fact that bankruptcy loss is an absorbing state and can be observed just once in a security's lifetime.

Although the model adopted in this paper is a highly streamlined version of reality, it produces a variety of interesting insights that come from the integration of well known aspects of the CAPM and option pricing model (OPM) into a single logical structure. The central result is a security valuation formula that is sensitive simultaneously to the benefits of limited liability and of portfolio diversification.

The balance of the paper is organized as follows: Section 2 motivates the problem. Section 3 provides a formal analysis of the model. Section 4 examines stock return anomalies by contrasting the revised and traditional approaches. Section 5 proposes feasible estimators for systematic risk that account for bankruptcy risk. Section 6 reviews the implications of the model and section 7 concludes.

\section{TWO EXPERIMENTS AND THE MODELING FRAMEWORK}

\subsection{General Idea}

In order to illustrate the impact of bankruptcy risk on estimates of fair stock prices I generate simulated equity and market returns, record a return of $-100 \%$ when the business fails, and then compute regression coefficients with and without total losses in the sample. Repeating this for different degrees of bankruptcy risk and market sensitivity gives a rough idea of the magnitude and direction of latent errors in conventional estimates of systematic risk. Since these 
simulations set the stage for a formal analysis of the problem, I preface them with a minimum set of necessary assumptions and definitions.

Imagine a risky enterprise that carries debt, functions in a single-period economy where the premises of the Sharpe-Lintner-Mossin CAPM apply, and whose prospective operating cash flows are correlated with market returns. To assume that the enterprise is risky means that operating cash flows cannot be predicted with certainty. To assume it carries debt implies that, if there is insufficient cash when payments to creditors come due, the firm will declare bankruptcy and all available cash will be transferred to creditors. Finally, supposing that cash flows are correlated with the market implies that the likelihood of total loss to shareholders depends jointly on the firm's operating risk, financial risk (leverage), and on the market's performance, i.e., bankruptcy risk has both idiosyncratic and systematic components by design.

\subsection{The Firm}

Let the firm own assets capable of generating net operating cash flows $X$ (a random variable with support on the set of real numbers) within one year. After one year existing assets are converted into cash and distributed to the firm's owners and creditors. There are no taxes. If the sum of principal and interest on loans-denoted $d$-exceeds the realized value of $X$, the firm is bankrupt. (Since the model has but a single period and all claims are settled at the end of that period, it does not distinguish between financial distress, default and bankruptcy, and bankruptcy implies complete loss of shareholders' investment.) Bankruptcy is costless, which means that in the event of bankruptcy the entire cash balance goes to the firm's creditors. Let $X_{E}$ stand for the payoff to shareholders (dividends.) Under limited liability $X_{E}$ is determined as follows:

$$
X_{E}=\max (X-d, 0)
$$

\subsection{The Firm and the Market}

The one-year return on the market portfolio $\left(R_{m}\right)$ has a joint bivariate normal distribution with the net operating cash flows generated by the business $(X)$. The joint distribution of $X$ and $R_{m}$ has marginals $\mathrm{N}\left(\mu_{X}, \sigma_{X}\right)$ and $\mathrm{N}\left(\bar{r}_{m}, \sigma_{m}\right)$ with correlation coefficient $\rho$ such that $-1<\rho<+1$, i.e., correlation between the firm and the market is never perfect. Also, the likelihood of $R_{m}$ being lower than $-100 \%$ is insignificant. ${ }^{2}$ I refer to the standard deviation of cash flows ( $\left.\sigma_{X}>0\right)$ as "operating risk" and to the correlation between cash flows and market returns $(\rho)$ as "market sensitivity," or just "sensitivity."

Assuming that $X$ is correlated with $R_{m}$ implies that bankruptcy risk is conditional on the market's performance, is contagious, and therefore must be priced. There exists abundant evidence that historical failure rates are indeed associated with the state of the economy (HELWEGE; KLEIMAN, 1997; MOODY'S, 2000; HILLEGEIST et al., 2004; VASSALOU; XING, 2004). Bankruptcy risk, designated $p$, is uniquely determined by expected cash flows, operating risk, and financial leverage $\left(\mu_{X}, \sigma_{X}, d\right)$ as follows:

$$
p=\operatorname{Pr}\{X \leq d\}=\int_{-\infty}^{\delta} \phi(u) d u=\Phi_{\delta}
$$

where: $\delta=\left(d-\mu_{X}\right) / \sigma_{X} ; \quad \Phi_{\delta}=\Phi(\delta)=\Phi(\delta \mid \mu=0 ; \sigma=1)$ is the standard normal cumulative probability function; and $\phi_{\delta}=\phi(\delta)=\phi(\delta \mid \mu=0 ; \sigma=1)$ is the standard normal density function. The probability of avoiding bankruptcy is defined as $\bar{\Phi}_{\delta}=1-\Phi_{\delta}=1-p$.

Expression (2) establishes a one-to-one relationship between the probability of bankruptcy and $\delta$. Financial risk (the numerator in $\delta$ ) increases as leverage increases. Operating risk (the denominator in $\delta$ ) increases with the variability of net operating cash flows. 
The probability of shareholders being "wiped out" $(p)$ increases monotonically with financial risk for any level of operating risk. But the direction of the relationship between the risk of failure and operating risk depends on whether $d<\mu_{X}$ or $d>\mu_{X}$. In the first case (relatively low leverage) $p$ rises with operating risk; in the second case (relatively high leverage) $p$ falls with operating risk.

\subsection{Security Prices}

I assume perfect capital markets with risk-averse quadratic utility investors whose beliefs and investment opportunities are similar. I assume quadratic utilities because: (1) the mean and variance are interdependent under truncated normal returns; and (2) mean-variance analysis holds despite non-normal returns and interdependent means and variances if utilities are quadratic (HALEY; SCHALL, 1979; DYBVIG; INGERSOLL, 1982). With these assumptions the equilibrium expected return on equity is:

$$
\mathrm{E}\left[R_{E}\right]=i+\beta_{E}\left(\bar{r}_{m}-i\right)
$$

where $i$ is the risk-free rate and $\beta_{E}$ is the systematic risk of equity, defined as:

$$
\beta_{E}=\frac{\operatorname{cov}\left(R_{E}, R_{m}\right)}{\sigma_{m}^{2}}
$$

Fair value of the firm's equity $\left(V_{E}\right)$ can be calculated either as the expected payoff to shareholders divided by a risk-adjusted discount factor:

$$
V_{E}=\frac{\mathrm{E}\left[X_{E}\right]}{1+\bar{R}_{E}}
$$

or as the "certainty-equivalent" payoff divided by one plus the risk-free rate:

$$
V_{E}=\frac{\mathrm{E}\left[X_{E}\right]-\lambda \operatorname{cov}\left(X_{E}, R_{m}\right)}{1+i}
$$

where $\lambda$, the "price of risk", is the Sharpe-measure $(s)$ divided by $\sigma_{m}$ :

$$
\lambda=\underbrace{\left(\frac{\bar{r}_{m}-i}{\sigma_{m}}\right)}_{\text {Sharpe-measure }} \frac{1}{\sigma_{m}}=\frac{s}{\sigma_{m}}
$$

Valuation formulas (5) and (6) are consistent with bankruptcy and limited liability (Mossin 1973). In addition, since all available cash is distributed to stakeholders upon liquidation (no taxes and no bankruptcy costs), the value of the firm itself is independent of leverage. If investors pay fair value for common stock as given by (5) or (6) and the liquidating dividend is $X_{E}$, then the holding-period return to shareholders is:

$$
R_{E}=\left(X_{E} / V_{E}\right)-1
$$

which, using (6), can be expressed as:

$$
R_{E}=\frac{X_{E}(1+i)}{\mathrm{E}\left[X_{E}\right]-\lambda \operatorname{cov}\left(X_{E}, R_{m}\right)}-1
$$

\subsection{Simulation Exercise No. 1 (Impact of Bankruptcy on Beta)}

In this exercise I run two types of regressions of stock returns on market returns. Returns are generated via the Monte Carlo method according to the assumptions above. In regressions of the first type I replicate traditional estimation of systematic risk (or beta) by removing from the sample all observations where $\hat{r}_{E}=-100 \%$. In regressions of the second type I leave those observations in. Of course, since $-100 \%$ returns are not recorded in practice the second type of regression is not implementable. Its purpose is to help assess the potential for error in the conventional estimation technique. 
I perform regressions for nine combinations of $p=.02, .05, .15$ (bankruptcy risk) with $\rho=.10, .30, .50$ (market sensitivity). Market parameters are assumed to be $\bar{r}_{m}=.15, \sigma_{m}=.20$ and $i=.05$. Simulated values of true beta $\left(\beta_{E}\right)$, OLS beta $\left(\beta_{E}^{O L S}\right)$, and the errors in expected returns that result from using $\beta_{E}^{\text {oLS }}$ are shown in Table 1 . As expected the values of true and OLS beta tend to increase with both $p$ and $\rho$. But note that all estimates of $\beta_{E}$ in Table 1 exceed the corresponding estimates of $\beta_{E}^{\text {oLS }}$. Therefore investors who use $\beta_{E}^{\text {oLS }}$ will underestimate required rates of return (and overvalue common stock) when bankruptcy risk and market sensitivity are within the assumed ranges.

Table 1. Simulated true beta, OLS beta and errors in required rates of return as a function of market sensitivity $(\rho)$ and bankruptcy risk $(p)$.

\begin{tabular}{|c|c|c|c|c|c|c|c|c|c|}
\hline \multicolumn{3}{|c|}{ True and OLS beta: } & \multicolumn{2}{|c|}{$\begin{array}{ll}\beta_{E} & \text { (top) } \\
\beta_{E}^{\text {oLS }} & \text { (bottom) } \\
\end{array}$} & \multicolumn{5}{|c|}{$\begin{array}{l}\text { Error in required rate of return: } \\
\bar{R}_{E}-\bar{R}_{E}^{\text {oLS }} \text { (basis points) }\end{array}$} \\
\hline & & $\begin{array}{l}\rho \\
.10\end{array}$ & .30 & .50 & $\begin{array}{l}\rho \\
.10\end{array}$ & .30 & .50 & & \\
\hline \multirow{3}{*}{$p$} & .02 & $\begin{array}{l}.266 \\
.225\end{array}$ & $\begin{array}{l}.808 \\
.753\end{array}$ & $\begin{array}{l}1.403 \\
1.318\end{array}$ & 41 & 55 & 85 & \multicolumn{2}{|l|}{.02} \\
\hline & .05 & $\begin{array}{l}.215 \\
.186\end{array}$ & $\begin{array}{l}1.079 \\
.904\end{array}$ & $\begin{array}{l}1.496 \\
1.378\end{array}$ & 29 & 151 & 118 & \multicolumn{2}{|l|}{.05} \\
\hline & .15 & $\begin{array}{l}.608 \\
.485\end{array}$ & $\begin{array}{l}1.192 \\
.945\end{array}$ & $\begin{array}{l}2.570 \\
2.248\end{array}$ & 123 & 247 & 322 & \multicolumn{2}{|l|}{.15} \\
\hline
\end{tabular}

Figure 2 illustrates in more detail the case for $p=.05$ and $\rho=.30$ (the market sensitivity level that corresponds to a beta of about one for this level of $p$.) The plot on the left excludes total losses and portrays the conventional estimation technique that produces $\beta_{E}^{\text {oLS }}=.904$. The plot on the right includes total losses and portrays an alternative technique that takes bankruptcy risk into account and leads to $\beta_{E}=1.079$. In this case OLS understates true beta by about $15 \%$ and required rates of return by 151 basis points (assuming that $\bar{r}_{m}=.15, \sigma_{m}=.20$ and $i=.05$.)

\subsection{Simulation Exercise No. 2 (Portfolio Aggregation Reduces Noise, Not Bias)}

After observing that a firm's OLS beta can be a significantly biased estimate of true beta it is natural to ask whether a portfolio's OLS beta would also be vulnerable to bias. Portfolios play a central role in tests of the CAPM because they minimize noise in beta. Since the chance of a portfolio returning $-100 \%$ drops sharply as the number of securities in the portfolio increases (even if the portfolio contains only very distressed securities), intuition suggests that the truncation effect on portfolio beta should be immaterial. But the simple algebra of portfolio beta indicates otherwise. Portfolio beta is a value-weighted average of the true betas of all securities in the portfolio. The usual estimator of portfolio beta is also a value-weighted average of the estimators of firm-specific betas, but only if all possible outcomes are included in the data. 
Figure 2. Partial and full sample regressions of $R_{E}$ vs. $R_{m}(p=.05 ; \rho=.30)$.

Partial sample (without $R_{E}=-100 \%$ )

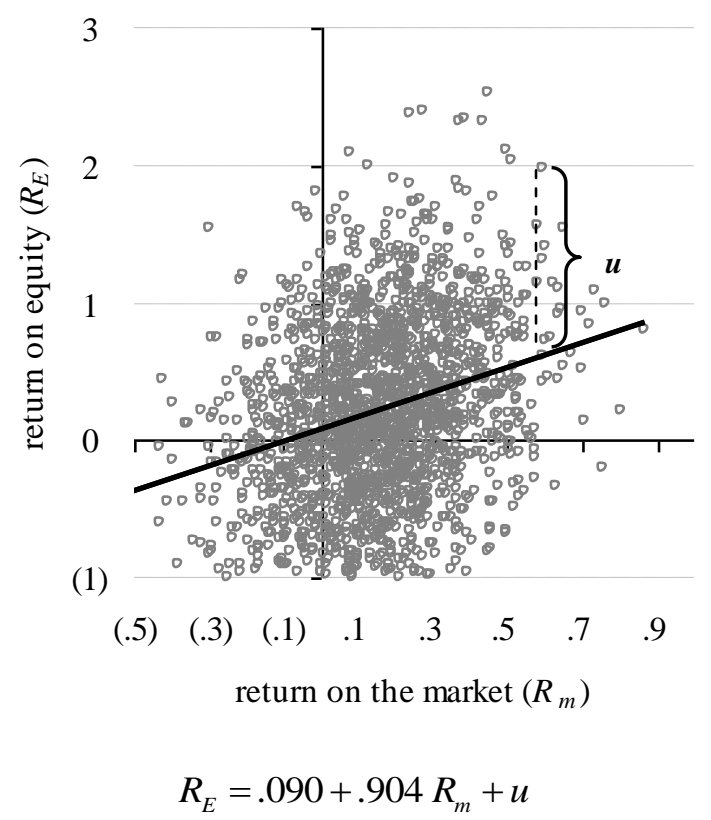

Full sample (with $R_{E}=-100 \%$ )

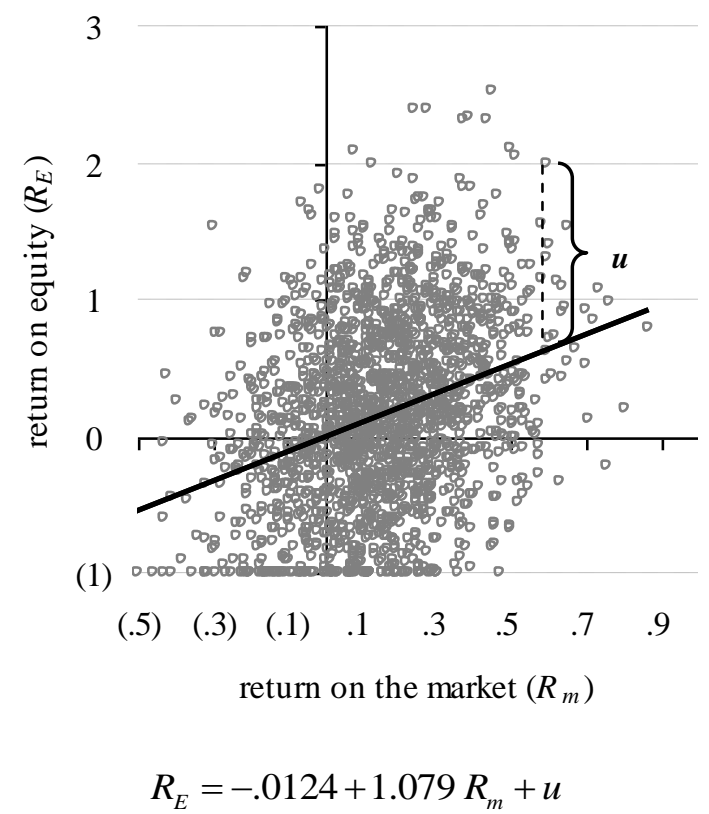

To illustrate the fact that portfolios deal with noise but not bias, I run Monte Carlo experiments with $p=.05$ (bankruptcy risk) and $\rho=.30$ (sensitivity). Market parameters are maintained at $\bar{r}_{m}=.15, \sigma_{m}=.20$ and $i=.05$. Averages and standard deviations for the simulated values of true betas $\left(\beta_{E}\right)$ and OLS betas $\left(\beta_{E}^{\text {oLS }}\right)$ for portfolio sizes between 1 and 20 are given in Table 2. As expected, the standard deviations of both true and OLS beta fall quickly as the number of securities in the portfolio increases, with about three quarters of the total reduction obtained with $N=20$ securities already obtained by $N=5$. There is, however, no apparent change in the amount by which OLS underestimates true beta: the absolute value of the bias in $\beta_{E}^{o L S}$ remains close to the theoretical value of .130 as the number of securities increases from 1 to 20 .

No doubt one can contrive scenarios in which portfolio betas are less affected by bias than individual securities by combining positive and negative biases. However, according to the formal analysis of the model in the next section of the paper, if bankruptcy risk is in the 0$25 \%$ range and sensitivity is less than .7, then all firm-specific OLS betas will underestimate true beta and so will portfolio OLS beta regardless of how many securities are in the portfolio.

Table 2. Noise and bias in estimated portfolio beta as a function of portfolio size.

\begin{tabular}{lllllllll}
\hline Portfolio Size $(N) \rightarrow$ & $1^{(*)}$ & $2^{(*)}$ & $5^{(*)}$ & $10^{(*)}$ & $15^{(*)}$ & $20^{(*)}$ & Theory $^{(+)}$ \\
\hline True beta $\left(\beta_{E}\right):$ & average & .976 & 1.001 & .998 & .992 & .986 & .980 & .982 \\
& std. dev. & .359 & .234 & .142 & .095 & .077 & .076 & \\
\hline \multirow{2}{*}{ OLS beta $\left(\beta_{E}^{\text {OLS }}\right):$ average } & .818 & .870 & .859 & .855 & .852 & .846 & .852 \\
& std. dev. & .317 & .220 & .146 & .093 & .076 & .070 & \\
Bias in OLS beta & $(.157)$ & $(.131)$ & $(.139)$ & $(.138)$ & $(.134)$ & $(.133)$ & $(.130)$
\end{tabular}

$\left(^{*}\right.$ Values in these columns are realizations of a random process, not theoretical predictions. ${ }^{(+)}$Theoretical values of true and OLS beta according to Propositions II and V presented later in the paper. 


\section{FORMAL ANALYSIS}

The Monte Carlo experiments above illustrate the impact of total losses in the calculation of firm-specific and portfolio betas and encourage a deeper discussion of valuation errors caused by overlooking bankruptcy risk. In order to do this successfully we need formal expressions for beta, expected returns and value of common stock. As a first step in this direction I take a closer look at the expected payout to shareholders, a key input in formulas (5) and (6) and for shareholder returns (9).

\subsection{Expected Payoff to Shareholders}

Intuitively expected dividends should go down with leverage ceteris paribus (because more leverage implies less of the same cash flows are available for shareholders) and rise with operating risk (because limited liability implies that any expansion in the upside is not entirely offset by the corresponding downside expansion.) Lemma 1 confirms this intuition, which is portrayed in Figure 3.

LEMMA 1. The expected value and standard deviation of dividends are determined by $\sigma_{X}$ (operating risk) and $\delta$ as follows:

$$
\begin{aligned}
& \mathrm{E}\left[X_{E}\right]=\sigma_{X} \mathrm{H}_{\delta 0} \\
& \sigma_{X_{E}}=\sigma_{X} \sqrt{\bar{\Phi}_{\delta}-\left(\delta+\mathrm{H}_{\delta 0}\right) \mathrm{H}_{\delta 0}}
\end{aligned}
$$

where $\mathrm{H}_{\delta 0}=\phi_{\delta}-\delta \bar{\Phi}_{\delta}$ is the expected dividend per unit of operating risk.

Figure 3. Expected dividends as a function of operating risk $\left(\sigma_{X}\right)$ and financial risk.

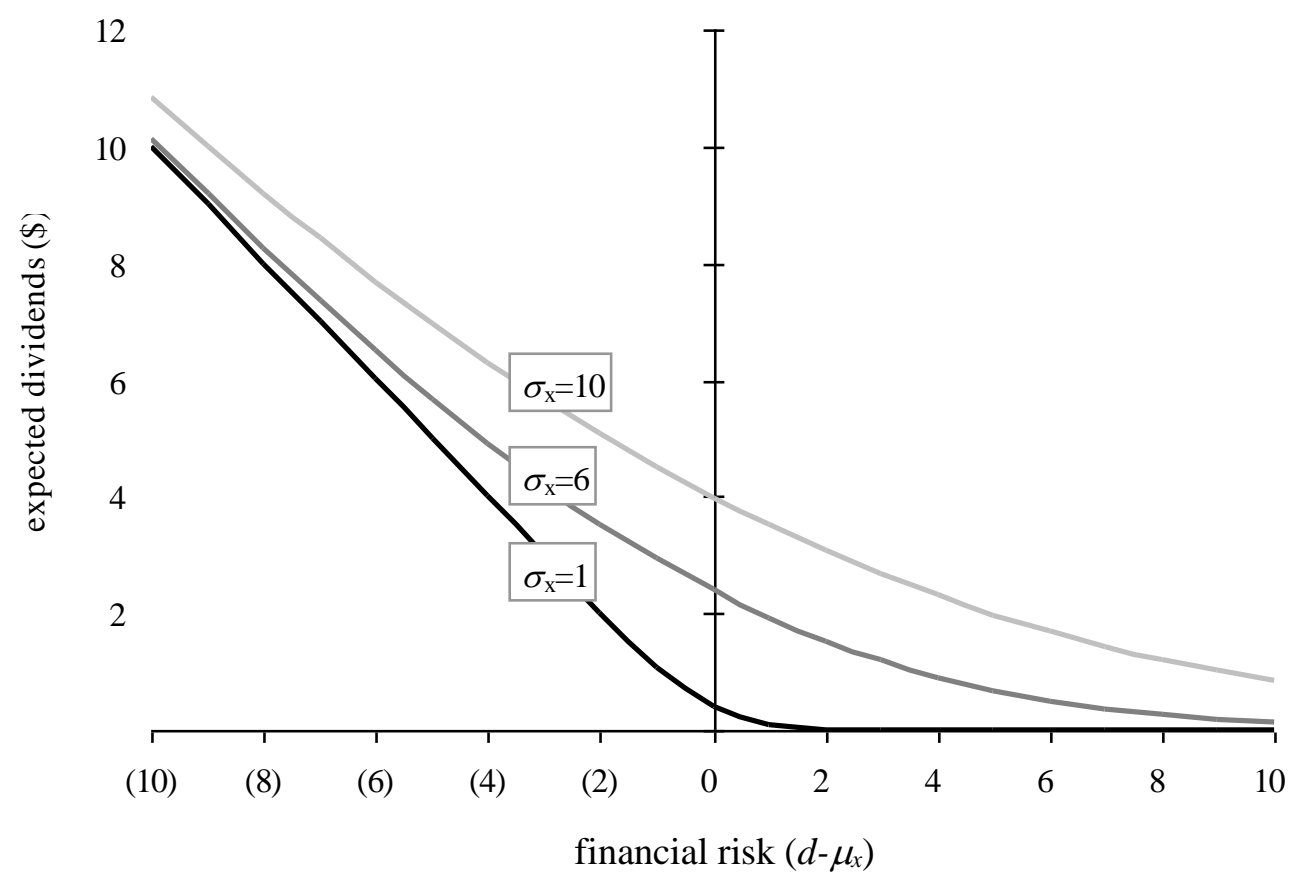

\subsection{Covariance of Cash Flows and Market Returns}

The covariance between dividends $\left(X_{E}\right)$ and market returns $\left(R_{m}\right)$ under limited liability is a key input both in the certainty-equivalent valuation formula (6) and in the closed-form expression for systematic risk to be obtained later on. In a large economy the range of variation in market returns is not much affected by what happens to a single firm, but the range of variation in a firm's dividends is strongly curtailed by limited liability as the likelihood of 
bankruptcy increases. Intuitively this should lead to a reduction in the covariance between $X_{E}$ and $R_{m}$ as $p$ increases. Lemma 2 shows that this intuition is correct:

LEMMA 2. The covariance between dividends and market returns under limited liability is equal to the covariance with unlimited liability attenuated by the probability of bankruptcy not happening $(1-p)$, as follows:

$$
\operatorname{cov}\left(X_{E}, R_{m}\right)=\underbrace{\rho \sigma_{X} \sigma_{m}}_{\begin{array}{c}
\text { covariance with } \\
\text { unlimited liability }
\end{array}}-\rho \sigma_{X} \sigma_{m}(p)=\underbrace{\rho \sigma_{X} \sigma_{m}(1-p)}_{\begin{array}{c}
\text { covariance with } \\
\text { limited liability }
\end{array}}
$$

Combining Lemma 2 (bankruptcy risk attenuates the covariance between dividends and market returns) with the fact that stock returns and dividends are positively related, does not imply that bankruptcy risk attenuates beta. In fact the opposite happens as we will see in Proposition II later on.

\subsection{Stock Returns}

The relationship between bankruptcy risk and stock returns is at the center of a vital research effort motivated by questions such as: - Do investors expect relatively higher or lower returns from stock in distressed firms (DICHEV, 1998; VASSALOU; XING 2004)? Or the opposite question: - How can historical stock return patterns be used to assess the likelihood of bankruptcy (Hillegeist et al. 2004)? Another fruitful line of inquiry was prompted by the finding that anomalous patterns in the cross-section of stock returns that had been attributed to size and leverage are effectively subsumed by bankruptcy risk (CHAN; CHEN 1991). These questions are related to the basic issue of what determines the distribution of stock returns. In terms of the model in Section 2, do expected cash flows, operating risk, leverage and market sensitivity affect stock returns, and if so, how? The answer is given in Proposition I.

PROPOSITION I. The effects of operating risk, expected cash flows and leverage on stock returns are subsumed by bankruptcy risk. Two firms with different expected cash flows, operating risk and leverage, but the same bankruptcy risk, produce identically distributed returns. Market sensitivity is separately related to returns. Stock returns have a truncated normal distribution as follows:

$$
R_{E} \sim \frac{(1+i) \max \left(0, Z_{X}-\delta\right)}{\mathrm{H}_{\delta \rho}}-1
$$

where $Z_{X}=\left(X-\mu_{X}\right) / \sigma_{X} \sim \mathrm{N}(0,1)$ and $\mathrm{H}_{\delta \rho}=\phi_{\delta}-(\delta+s \rho) \bar{\Phi}_{\delta}$.

COROLLARY. The only firm-specific characteristics that affect equity beta are $p$ and $\rho$.

Proposition I suggests the elements of an explanation for why distress subsumes the effects of size and leverage in CAPM anomalies. It also suggests an explanation for why longrun stock returns on distressed firms can be lower than those on healthy firms (DICHEV, 1998) by emphasizing that market sensitivity also matters in the determination of systematic risk.

\subsection{True Beta}

I use the qualifier "true" to distinguish the value of beta which takes into account the possibility of bankruptcy from its ordinary least squares proxy. According to the CAPM, beta measures risk that cannot be diversified away in a portfolio and therefore should be priced. This is the essence of expression (3), which states that investors expect the riskless rate plus beta times the market premium when buying common stock. According to the corollary to Proposition I true beta depends only on bankruptcy risk and market sensitivity, besides the usual market parameters. The next proposition adds a closed-form expression for computing true beta.

PROPOSITION II. True equity beta is determined by bankruptcy risk, sensitivity and the market's parameters as follows: 


$$
\beta_{E}=\frac{\rho(1+i) \bar{\Phi}_{\delta}}{\sigma_{m} \mathrm{H}_{\delta \rho}}
$$

Figure 4 contains plots of $\beta_{E}$ as a function of $p$ for selected values of $\rho$. (Table 3 shows theoretical values of $\beta_{E}$ for selected values of $p$ and $\rho$.) Observe that $\beta_{E}$ increases with $\rho$, given $p$ and increases with $p$, given $\rho$. This agrees with intuition and is confirmed by a formal analysis of partial derivatives. The multiple connections of $\beta_{E}$ with leverage, operating risk and market sensitivity embedded in Proposition II are well documented in the literature (Bowman 1979; Mandelker and Ghon Rhee 1984).

A recently observed aspect of the connection between bankruptcy risk and $\beta_{E}$ is that there have been times when firms with high bankruptcy risk persistently yielded stock returns that are lower than average market-wide returns (Dichev 1998). This seems to contradict the CAPM.

Table 3: True Beta, OLS Beta, and Predicted Unconditional Return Anomalies (with market parameters at: $\bar{r}_{m}=.15, \sigma_{m}=.20$, and $i=.05$ ).

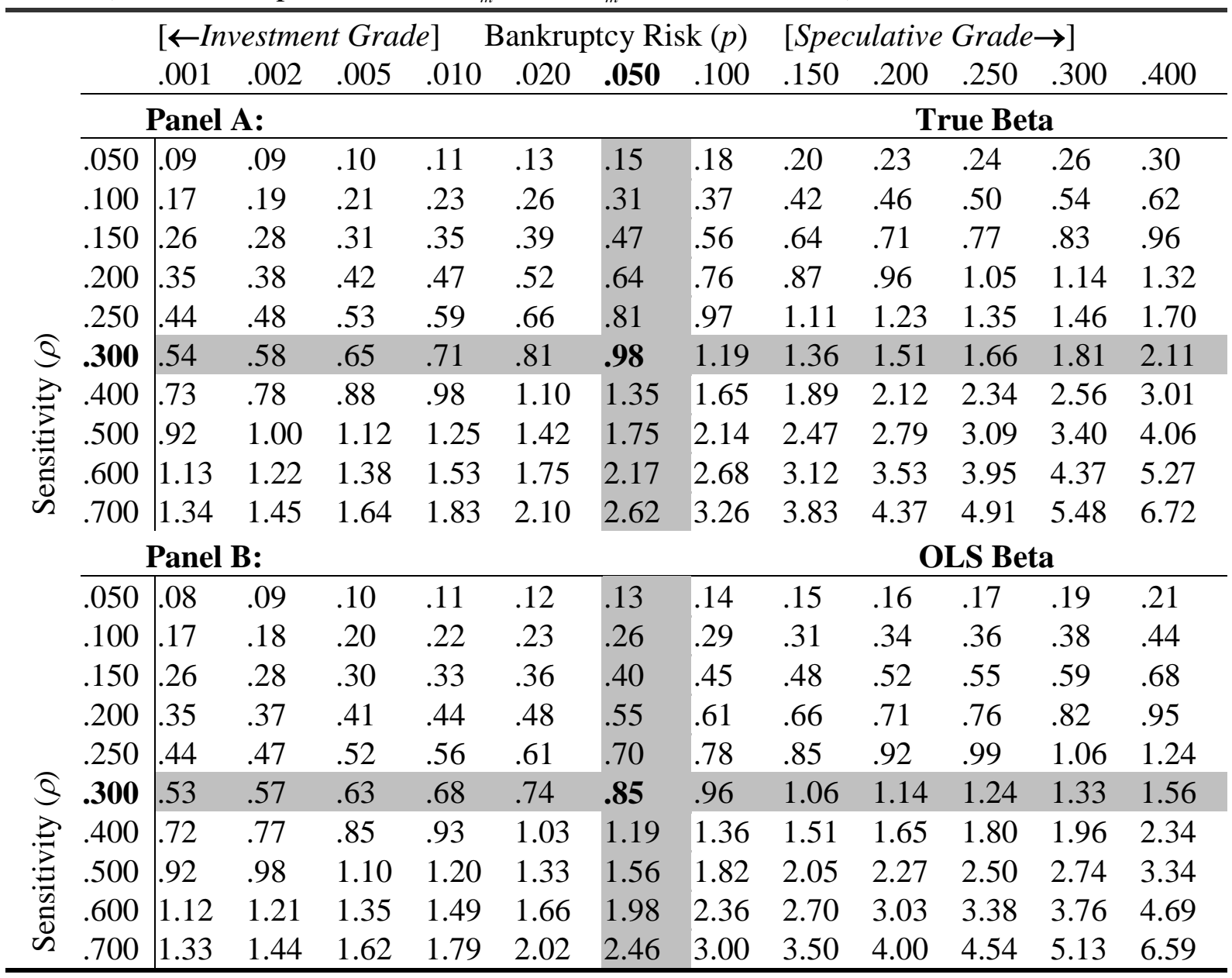




\begin{tabular}{|c|c|c|c|c|c|c|c|c|c|c|c|c|c|}
\hline & \multicolumn{3}{|c|}{ Panel C: } & \multicolumn{9}{|c|}{ Unconditional Return Anomalies (in basis points) } & \multirow[b]{2}{*}{89} \\
\hline \multirow{10}{*}{ 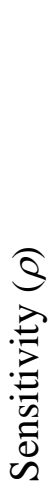 } & .050 & 1 & 1 & 3 & 6 & 11 & 22 & 38 & 50 & 61 & 70 & 78 & \\
\hline & .100 & 2 & 3 & 7 & 12 & 22 & 45 & 76 & 102 & 123 & 142 & 158 & 181 \\
\hline & .150 & 2 & 4 & 10 & 18 & 32 & 68 & 114 & 153 & 186 & 215 & 240 & 275 \\
\hline & .200 & 3 & 6 & 13 & 24 & 43 & 90 & 152 & 204 & 249 & 288 & 321 & 368 \\
\hline & .250 & 4 & 7 & 16 & 30 & 53 & 111 & 189 & 254 & 310 & 358 & 400 & 459 \\
\hline & .300 & 5 & 8 & 19 & 35 & 62 & 131 & 223 & 300 & 367 & 425 & 474 & 543 \\
\hline & .400 & 6 & 11 & 24 & 43 & 77 & 164 & 281 & 379 & 464 & 537 & 598 & 676 \\
\hline & .500 & 6 & 12 & 26 & 48 & 87 & 184 & 316 & 426 & 520 & 598 & 660 & 720 \\
\hline & .600 & 6 & 12 & 27 & 49 & 88 & 184 & 314 & 419 & 504 & 567 & 606 & 588 \\
\hline & .700 & 6 & 11 & 24 & 43 & 77 & 157 & 257 & 327 & 367 & 376 & 346 & 123 \\
\hline
\end{tabular}

Formulas: $\quad$ Panel A: $\beta_{E}=\rho(1+i) \bar{\Phi}_{\delta} /\left[\sigma_{m} \mathrm{H}_{\delta \rho}\right]$

Panel B: $\beta_{E}^{o l s}=\rho(1+i)\left[\bar{\Phi}_{\delta}^{2}-\phi_{\delta} \mathrm{H}_{\delta 0}\right] /\left(\sigma_{m} \mathrm{H}_{\delta \rho}\left[\bar{\Phi}_{\delta}^{2}-\rho^{2} \phi_{\delta} \mathrm{H}_{\delta 0}\right]\right)$

Panel C: $\mathrm{E}\left[R_{E}\right]-\mathrm{E}\left[R_{E}\right]^{*}=\left(\beta_{E}-\beta_{E}^{o L S}\right)\left(\bar{r}_{m}-i\right)$

However, according to Proposition II, the effect on $\beta_{E}$ of increasing distress levels depends on market sensitivity. (See Figure 4.) If in Dichev's sample sensitivity is sufficiently smaller for the most distressed firms, then the finding that returns on distressed portfolios are lower than returns on healthy portfolios does not contradict the CAPM.

Figure 4. True and OLS betas vs. bankruptcy risk and market sensitivity.

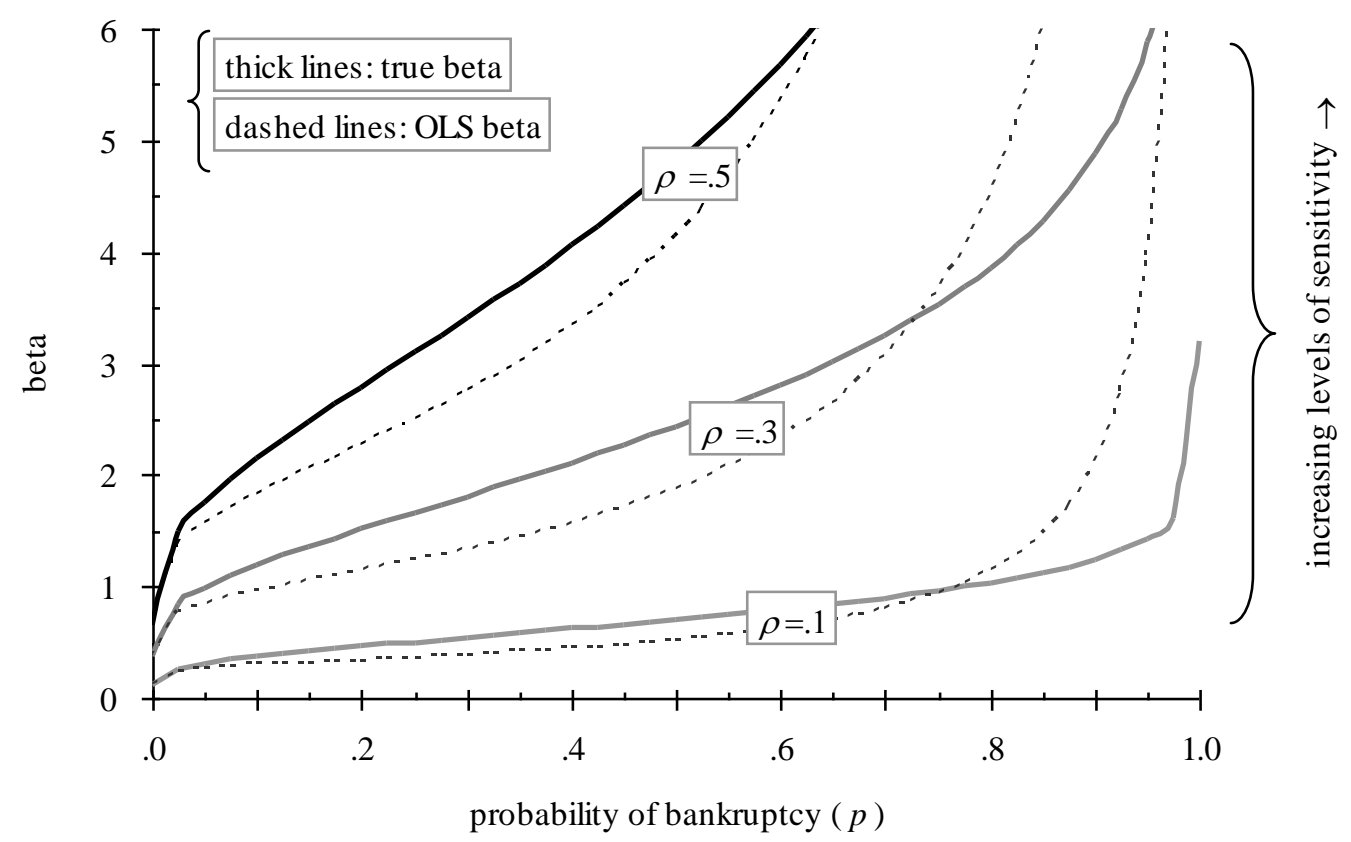

\subsection{Fair Value of Equity}

In order to obtain a valuation formula for common stock that reflects jointly the benefits of diversification and of the "option to abandon" I substitute in (5) expressions for expected dividends and expected returns that consider the risk of bankruptcy loss to shareholders. The 
result is stated below.

PROPOSITION III. Fair value of equity is determined by probability of bankruptcy loss (there is a one-to-one relationship between $p$ and $\delta$ ), sensitivity, operating risk and market parameters as follows:

$$
V_{E}=V_{E}^{C A P M}=\frac{\sigma_{X} \mathrm{H}_{\delta \rho}}{1+i}
$$

COROLLARY $1 . \mathrm{H}_{\delta \rho}=\phi_{\delta}-(\delta+s \rho) \bar{\Phi}_{\delta}$ is the certainty equivalent measure of dividend per unit of operating risk $\left(\sigma_{X}\right)$. The expected dividend per unit of operating risk is simply $\mathrm{H}_{\delta \rho}$ when $\rho=0$, or $\mathrm{H}_{\delta 0}$.

COROLLARY 2. Value of equity can be expressed as the ratio of volatility of dividends to the volatility of returns on equity:

$$
V_{E}=V_{E}^{C A P M}=\frac{\sigma_{X_{E}}}{\sigma_{R_{E}}}
$$

COROLlARY 3. The value of total assets $\left(V_{A}\right)$ does not depend on financial leverage $(d)$.

COROLlARY 4. The standard deviation of returns on equity is determined by $p, \rho$, and market parameters, as follows:

$$
\sigma_{R_{E}}=\frac{\sigma_{X_{E}}(1+i)}{\sigma_{X} \mathrm{H}_{\delta \rho}}
$$

where $\sigma_{X_{E}}$ is given by expression (11).

Expression (17) shows that total risk $\left(\sigma_{R_{E}}\right)$ is inversely proportional to a factor $\left(H_{\delta \rho}\right)$ that is affected by the correlation with market returns. Thus $\sigma_{R_{E}}$ cannot be written as the sum of two terms, one associated only with market risk and the other only with firm-specific risk, as required by the index model (BODIE; KANE; MARCUS, 1993). Nevertheless additive risk decomposition remains valid in the limit as the likelihood of bankruptcy tends to zero because:

$$
\lim _{p \rightarrow 0} \sigma_{R_{E}}^{2}=\left(\frac{1+i}{\mathrm{H}_{\delta \rho}}\right)^{2}=\frac{\beta_{E}^{2} \sigma_{m}^{2}}{\rho^{2}}=\frac{\text { systematic risk of security }}{\text { security characteristic line's R-squared }}
$$

\subsection{CAPM vs. OPM}

The most interesting aspect of Proposition III is that it incorporates in a single formula both the diversification and the option features of common stock. This can be seen by comparing the value of common stock as given by the CAPM (expression 15) with the value of common stock according to the option pricing model. For the firm described in Section 2, the value of equity according to the Black-Scholes option pricing model is:

$$
\left\{\begin{aligned}
V_{E}^{O P M} & =V_{A} \Phi_{g_{1}}-e^{-i} d \Phi_{g_{2}} \\
g_{1} & =\frac{1}{\sigma_{R_{A}}}\left[i+\frac{\sigma_{R_{A}}^{2}}{2}+\ln \left(\frac{V_{A}}{d}\right)\right] \\
g_{2} & =g_{1}-\sigma_{R_{A}}
\end{aligned}\right.
$$

where $V_{A}$ is the value of the firm's assets (the "underlying"), and $\sigma_{R_{A}}$ is the standard deviation of asset returns ("volatility"). 
Figure 5. Does the CAPM capture the option effect?

(5.1) Value of equity (vs. $V_{A}$ )

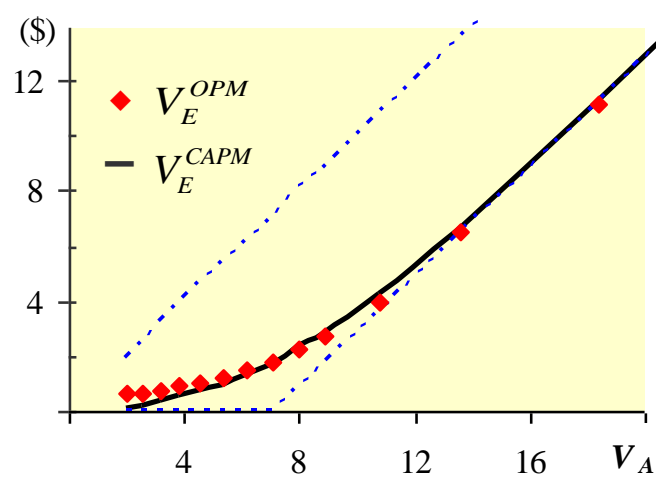

(5.3) "Volatility" $\sigma_{R_{A}}\left(\right.$ vs. $\left.V_{A}\right)$

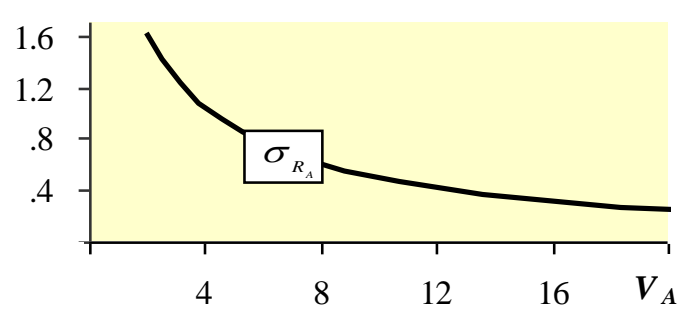

(5.2) Difference in $V_{E}$ and $p$ (vs. $\left.V_{A}\right)$

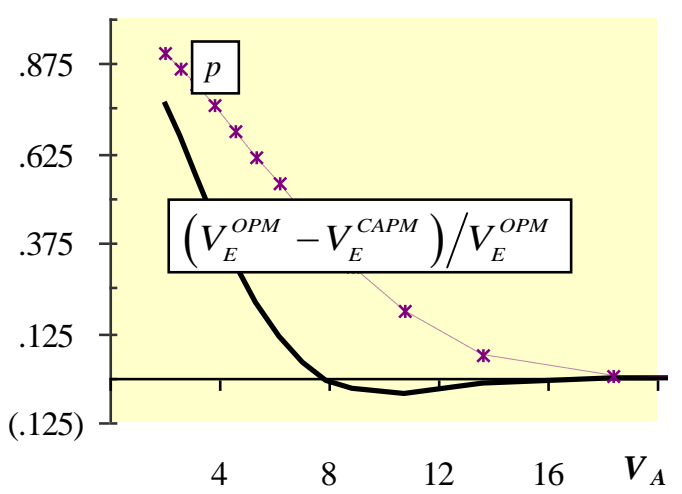

(5.4) Equity beta (vs. $V_{A}$ )

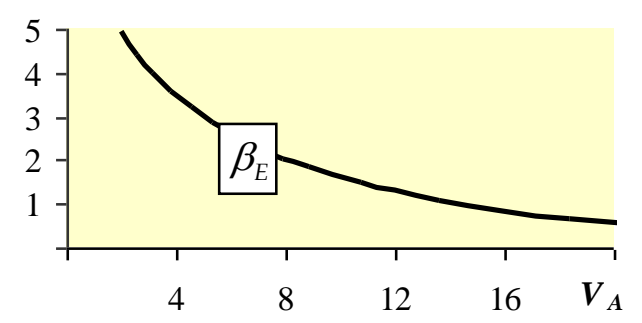

Results of changing the expected value of operating cash flows $\left(\mu_{X}\right)$ from $\$ 1$ to $\$ 35$. Given: $\sigma_{X}=\$ 5, d=\$ 7.5$ $\rho=.30$, and market parameters as usual at $\bar{r}_{m}=.15, \sigma_{m}=.20$ and $i=.05$.

To verify whether the CAPM captures the option feature of common stock I contrast the behavior of $V_{E}^{C A P M}$ with that of $V_{E}^{O P M}$ in two experiments. In the first I change the expected value of operating cash flows $\mu_{X}$ while keeping all other parameters of the model (expression 15) constant. In the second I change the standard deviation of operating cash flows $\sigma_{X}$ while keeping all other parameters constant. Results of the first experiment are shown in Figure 5. Panel 5.1 traces equity values calculated by the CAPM and OPM with respect to underlying asset prices $V_{A}$. As $V_{A}$ increases equity values under both models increase and converge to their lower bound at $\max \left[0, V_{A}-d(1+i)^{-1}\right]$. This is as anticipated (BREALEY et al., 2006). However, as seen in panel 5.2, the two valuations are not identical. At low asset prices $V_{E}^{O P M}>V_{E}^{C A P M}$. The situation reverses as asset prices increase, and the gap eventually disappears as $p \rightarrow 0$. Panels 5.3 and 5.4 show that both volatility $\left(\sigma_{R_{A}}\right)$ and equity beta $\left(\beta_{E}\right)$ decrease with asset values in this example. 
Figure 6. Does the CAPM capture the option effect?

(6.1) Value of equity (vs. $\sigma_{R_{A}}$ )

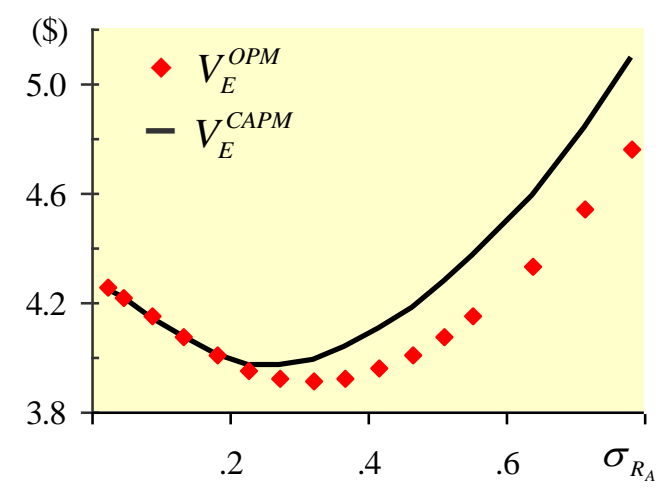

(6.3) Value of assets (vs. $\sigma_{R_{A}}$ )

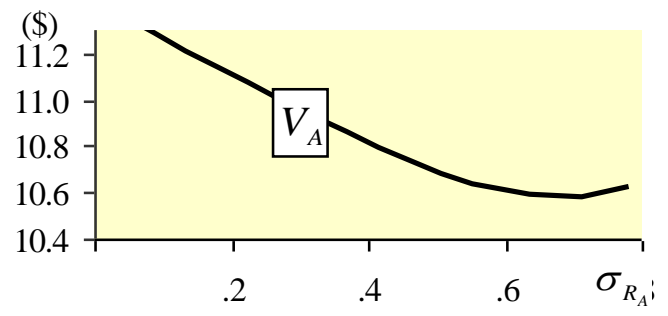

(6.2) Difference in $V_{E}$ and $p\left(\right.$ vs. $\left.\sigma_{R_{A}}\right)$

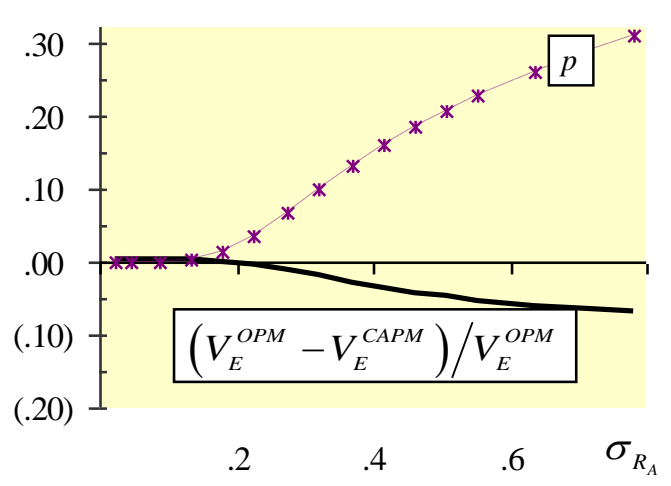

(6.4) Equity beta (vs. $\sigma_{R_{A}}$ )

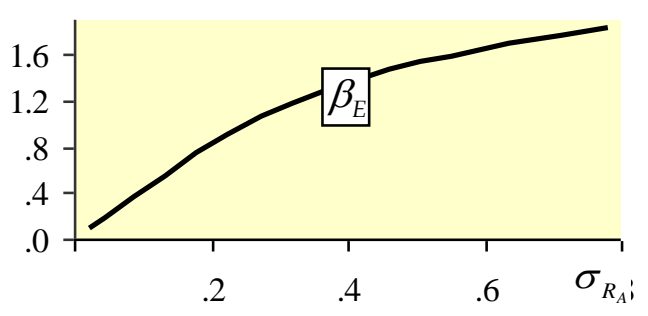

Results of changing the standard deviation of operating cash flows $\left(\sigma_{X}\right)$ from $\$ 0.25$ to $\$ 9.00$. Given: $\mu_{X}=\$ 12$ ,$d=\$ 7.5 \rho=.30$, and market parameters as usual at $\bar{r}_{m}=.15, \sigma_{m}=.20$ and $i=.05$.

Results of the second experiment are given in Figure 6. Panel 6.1 traces equity values calculated by the CAPM and OPM as a function of the volatility of asset returns $\left(\sigma_{R_{A}}\right)$. As volatility increases equity values under both models at first drop, and then rise. According to option pricing theory the direct effect of increasing $\sigma_{R_{A}}$ on the value of equity is positive, but the indirect effect could lead to a negative overall impact on the value of equity (BREALEY et al., 2006.)

As seen in panel 6.2, once again the two valuations are not identical: $V_{E}^{O P M}$ is slightly higher than $V_{E}^{C A P M}$ at low volatilities. As volatility rises (along with bankruptcy risk) the situation reverses and the gap continues to expand from then on. The explanation for the "U"shaped equity value curve is given from different perspectives by the OPM and by the CAPM. According to the OPM the effect of falling underlying asset prices (panel 6.3) is initially stronger than the effect of increasing volatility, but the situation eventually reverses. According to the CAPM the effect of increasing beta (panel 6.4) is initially stronger than the effect of increasing expected dividends, but the situation eventually reverses.

Figures 5 and 6 show that valuation formula (15) is sensitive to the shareholder benefits of both diversification and limited liability (the option effect). Discrepancies between the CAPM and OPM valuation formulas (15 and 19) are caused by different assumptions regarding the behavior of dividends. The CAPM (as applied in this paper) assumes that dividends follow a normal distribution truncated below at zero (the event "zero dividends" having positive probability equal to $p$ ) and that the variance of asset prices changes as asset prices change. The OPM assumes that asset prices follow a lognormal distribution (the event "zero dividends" having probability zero) and that the variance of asset prices is invariant with respect to asset 
prices. ${ }^{3}$

\subsection{Conditional Expected Returns}

According to the CAPM the unconditional expected return on equity is given by $\mathrm{E}\left[R_{E}\right]=i+\beta_{E}\left(\bar{r}_{m}-i\right)$ with the impact of bankruptcy risk given by Proposition II. Sometimes it is necessary to compute expected returns conditional on a given value of the market return, for example, when measuring investment performance by means of abnormal returns on equity (GRINBLATT; TITMAN, 1994; BREALEY et al., 2006). What is the correct manner of revising expected returns once we know that the realized value of $R_{m}$ turned out to be $\hat{r}_{m}$ ? Intuitively as long as operating cash flows and market returns are correlated $(\rho \neq 0)$ the answer should not be obtained simply by replacing $\hat{r}_{m}$ for $\bar{r}_{m}$ in (4) because knowledge of what happened to the market is useful for updating the firm's risk of bankruptcy loss and expected dividends. The correct way of computing the expected return on equity conditional on the market's outcome is given in Proposition IV, after preliminary results in Lemmas 3, 4 and 5.

LEMMA 3. Given that $R_{m}=\hat{r}_{m}$, the probability of bankruptcy loss to investors should be revised to:

$$
\hat{p}=\operatorname{Pr}\left\{X \leq d \mid R_{m}=\hat{r}_{m}\right\}=1-\bar{\Phi}_{\hat{\delta}}
$$

where: $\hat{\delta}=\left(\delta-\hat{\mu}_{Z}\right) / \hat{\sigma}_{Z} ; \hat{\mu}_{Z}=\rho\left(\hat{r}_{m}-\bar{r}_{m}\right) / \sigma_{m} ;$ and $\hat{\sigma}_{Z}=\sqrt{1-\rho^{2}}$

$\hat{\mu}_{Z}$ and $\hat{\sigma}_{Z}$ are location and variability measures for standardized cash flows $\left(Z_{X}\right)$ conditional on $R_{m}=\hat{r}_{m}$. The subscript of $\bar{\Phi}$ in (20) is a measure of risk similar to $\delta$ but revised in light of knowledge that $R_{m}=\hat{r}_{m}$.

LEMMA 4. The expected value of cash flows conditional on the firm not failing, given that the observed return on the market is $R_{m}=\hat{r}_{m}$ is given by:

$$
\mathrm{E}\left[X \mid X>d, R_{m}=\hat{r}_{m}\right]=d+\sigma_{X}\left(\hat{\mu}_{Z}-\delta+\frac{\hat{\sigma}_{Z} \phi_{\hat{\delta}}}{\bar{\Phi}_{\hat{\delta}}}\right)
$$

LEMMA 5. The ratio of conditional to unconditional expected dividends is:

$$
\hat{k}=\frac{\mathrm{E}\left[X_{E} \mid R_{m}=\hat{r}_{m}\right]}{\mathrm{E}\left[X_{E}\right]}=\frac{\hat{\sigma}_{Z} \mathrm{H}_{\hat{\delta} 0}}{\mathrm{H}_{\delta 0}}
$$

We are now ready to obtain an expression for conditional expected returns on equity that uses all information about the firm contained in the fact that $R_{m}=\hat{r}_{m}$.

PROPOSITION IV. The expected return on equity given that $R_{m}=\hat{r}_{m}$ is a function of beta, of the ratio of conditional to unconditional expected dividends $(\hat{k})$ and of market parameters, as follows: ${ }^{4}$

$$
\mathrm{E}\left[R_{E} \mid R_{m}=\hat{r}_{m}\right]=\hat{k}\left(1+\mathrm{E}\left[R_{E}\right]\right)-1
$$


Figure 7. New and traditional conditional expected returns $(p=.10 ; \rho=.50)$.

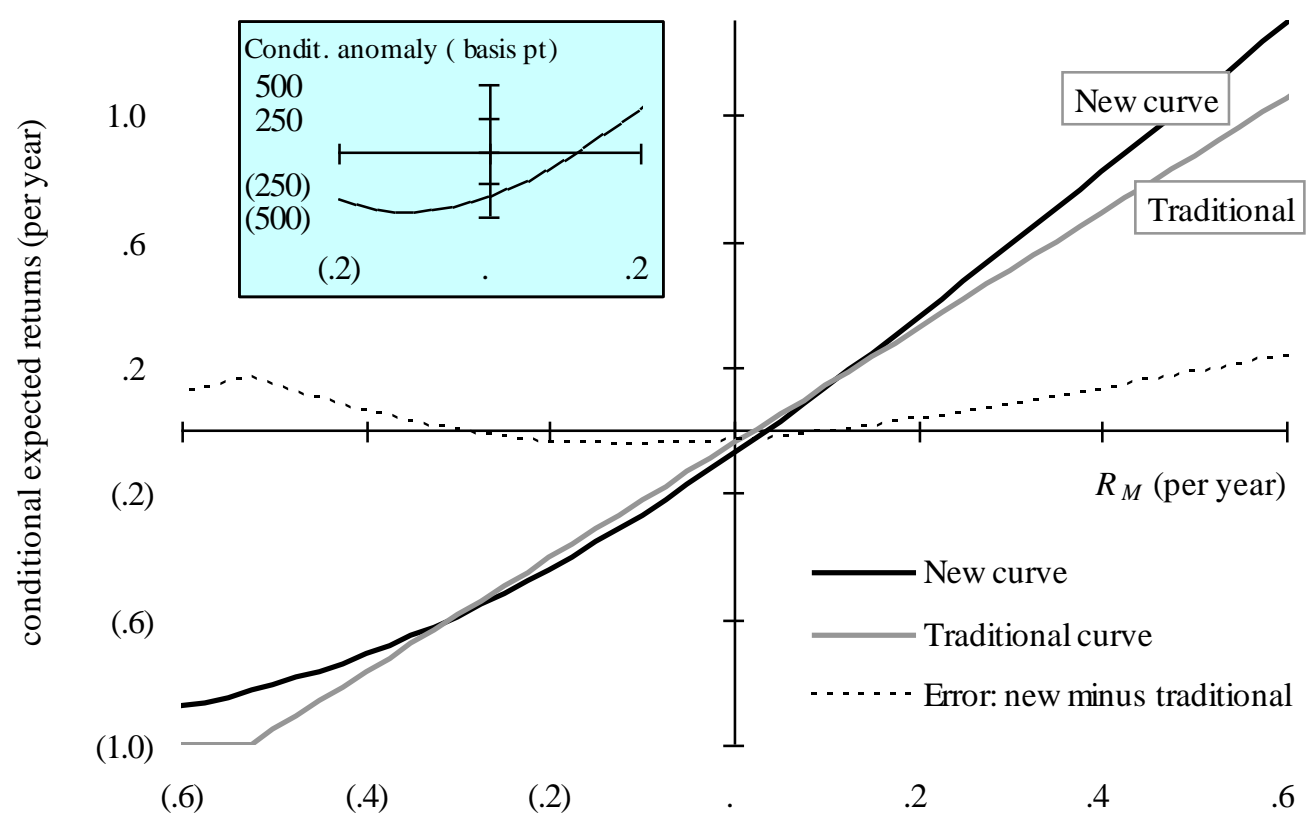

Proposition IV confirms that if market sensitivity is nonzero conditional expected returns cannot be obtained simply by substituting $\hat{r}_{m}$ for $\bar{r}_{m}$ in (3). It also shows that $\mathrm{E}\left[R_{E} \mid R_{m}=\hat{r}_{m}\right]$ is nonlinear in $\hat{r}_{m}$ and strictly respects limited liability, since $\lim _{\hat{R}_{m} \rightarrow-\infty}$ $\mathrm{E}\left[R_{E} \mid R_{m}=\hat{r}_{m}\right]=-100 \%$. This contrasts with the traditional approach of assuming that $\mathrm{E}\left[R_{E} \mid R_{m}=\hat{r}_{m}\right]=i+\beta_{E}\left(\hat{r}_{m}-i\right)$, which is linear in $\hat{r}_{m}$. Figure 7 contrasts the new and traditional approaches for computing conditional expected returns assuming that $p=.10$ and $\rho=.50$. A financial analyst who uses the traditional approach for this company will be negatively surprised when $\hat{r}_{m} \in(-.27, .13)$, and positively surprised when $\hat{r}_{m}>.13$. The relationship portayed in Figure 7 shows that even though the level of return on the market at which the firm's stock hits the lower bound is too low to be realistic, respecting the lower bound affects conditional expected returns over the entire range of market returns.

\section{CONSEQUENCES OF IGNORING BANKRUPTCY RISK}

According to Proposition II, beta is determined by two, and only two, firm-specific parameters: bankruptcy risk and market sensitivity. In practice beta is typically estimated by regressing historical rates of return on market rates of return using ordinary least squares (OLS). This section examines the consequences of ignoring the possibility of total losses when estimating beta.

\subsection{Impact on Estimates of Beta}

To examine the possibility of bias in traditional OLS estimates of beta I derive an expression for the covariance to variance ratio assuming that total losses are not recorded in the estimation sample. In other words, since OLS is employed to estimate the covariance to variance ratio as if all possible outcomes were available, what the conventional technique actually measures is the covariance to variance ratio conditional on total loss not happening, 
which means that:

$$
\beta_{E}^{\text {oLS }}=\frac{\operatorname{cov}\left(R_{E}, R_{m} \mid R_{E}>-1\right)}{\operatorname{var}\left(R_{m} \mid R_{E}>-1\right)}
$$

The next proposition offers an expression for $\beta_{E}^{O L S}$ in terms of fundamental parameters of the firm and market.

PROPOSITION V. The OLS estimator of equity beta conditional on total loss not happening can be written as a function of two, and only two, firm-specific parameters-bankruptcy and sensitivity - and the usual market parameters as follows:

$$
\beta_{E}^{o L S}=\frac{\rho(1+i)}{\sigma_{m} \mathrm{H}_{\delta \rho}} \times \frac{\bar{\Phi}_{\delta}^{2}-\phi_{\delta} \mathrm{H}_{\delta 0}}{\bar{\Phi}_{\delta}^{2}-\rho^{2} \phi_{\delta} \mathrm{H}_{\delta 0}}
$$

Figure 8 contains plots of $\beta_{E}^{\text {oLS }}$ versus $p$ for selected values of $\rho$ superimposed on plots of $\beta_{E}$ versus $p$. (Table 3 shows calculated values of $\beta_{E}^{\text {oLS }}$ for selected values of $\rho$ and $p$.) The graph shows that $\beta_{E}^{\text {oLS }}$ underestimates true beta for a wide range of realistic combinations of $\rho$ and $p$. It also shows that, as bankruptcy risk tends to zero, $\beta_{E}^{o L S}$ tends to true beta, whatever the degree of market sensitivity, i.e., $\lim _{p \rightarrow 0} \beta_{E}^{\text {oLS }}=\beta_{E}$. From Propositions II and V we conclude that:

COROLLARY. Market parameters have no effect on the ratio $\beta_{E} / \beta_{E}^{\text {oLS }}$, which depends only on bankruptcy risk and market sensitivity, as follows:

$$
\frac{\beta_{E}}{\beta_{E}^{\text {oLS }}}=\bar{\Phi}_{\delta}\left[\frac{\bar{\Phi}_{\delta}^{2}-\rho^{2} \phi_{\delta} \mathrm{H}_{\delta 0}}{\bar{\Phi}_{\delta}^{2}-\phi_{\delta} \mathrm{H}_{\delta 0}}\right]
$$

Figure 8. Ratio of true to OLS beta as function of bankruptcy risk $(p)$ and sensitivity $(\rho)$

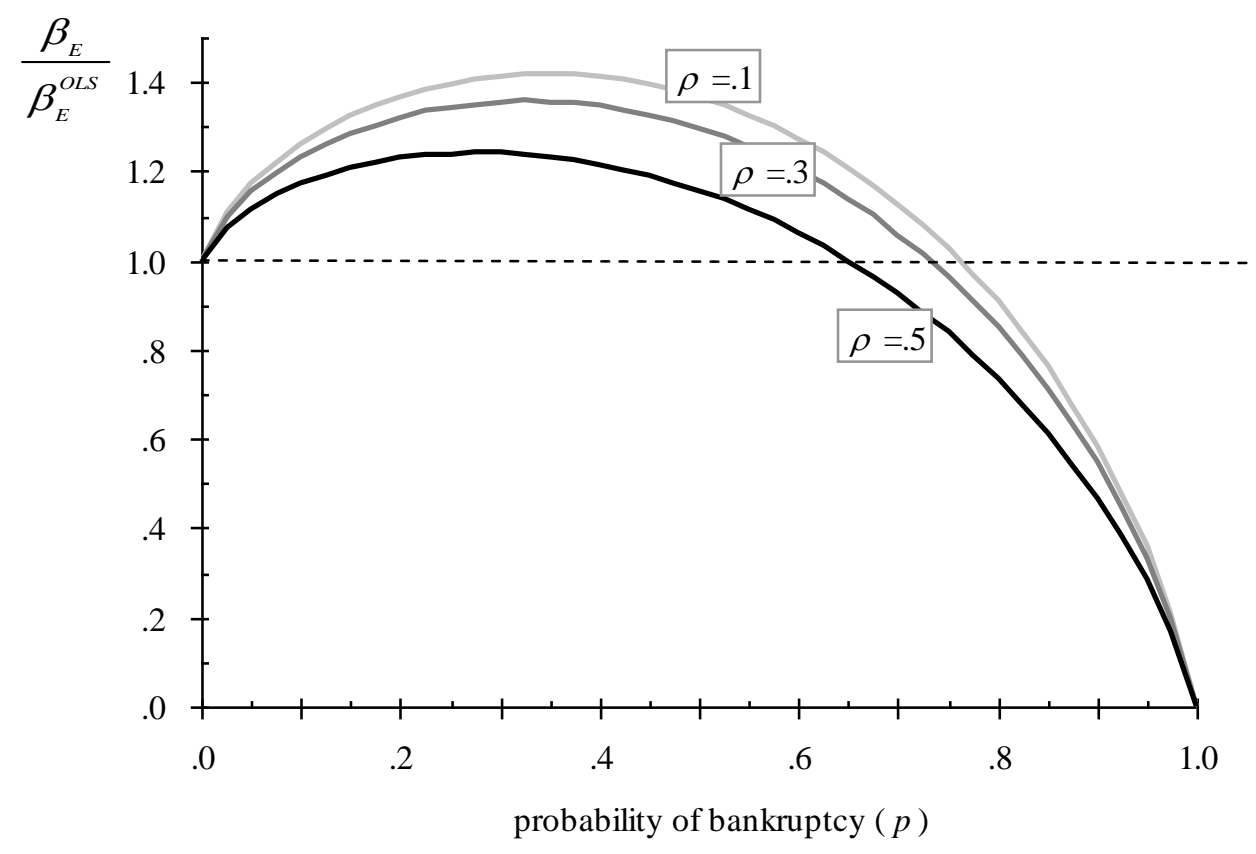

Figure 8 shows how the error in OLS estimates of beta varies with bankruptcy risk and sensitivity. Observe that $\lim _{p \rightarrow 0} \beta_{E} / \beta_{E}^{\text {oLS }}=1$ and that $\beta_{E} / \beta_{E}^{O L S}$ is a decreasing function of $\rho$ at any given $p$. Significant errors occur even at relatively low levels of bankruptcy risk. For example, at $p=.02$ and $\rho=.30, \beta_{E}$ is approximately $1.083 \times \beta_{E}^{O L S}$ and at the assumed market 
parameters required rates of return would be understated by more than half a percentage point (about 62 basis points.)

\subsection{Impact on Estimates of Required Returns}

To what extent are analysts who overlook the possibility of total losses surprised by actual returns? The answer to this question depends on whether the analyst presumably knows or does not know the actual market yield.

Assume first that the analyst is unsure about the actual market return $\left(R_{m}\right)$, but has formed an expectation for $R_{m}$ of $\bar{r}_{m}$. Let $\mathrm{E}\left[R_{E}\right]^{*}=i+\beta_{E}^{o L S}\left(\bar{r}_{m}-i\right)$ denote the conventionally computed ex-ante expected return on a firm's common stock based on OLS beta. I define unconditional anomaly as the difference between expected returns that take bankruptcy risk into account and expected returns that ignore bankruptcy risk, i.e., $\mathrm{E}\left[R_{E}\right]-\mathrm{E}\left[R_{E}\right]^{*}$.

PROPOSITION VI. Unconditional anomalies depend only on probability of bankruptcy, sensitivity and market parameters as follows:

$$
\underbrace{\mathrm{E}\left[R_{E}\right]}_{\text {TRUE }}-\underbrace{\mathrm{E}\left[R_{E}\right]^{*}}_{\text {OLS }}=\left(\beta_{E}-\beta_{E}^{\text {OLS }}\right)\left(\bar{r}_{m}-i\right)
$$

Now assume that the analyst knows $R_{m}=\hat{r}_{m}$, and let $\mathrm{E}\left[R_{E} \mid \hat{r}_{m}\right]^{*}=i+\beta_{E}^{\text {oLS }}\left(\hat{r}_{m}-i\right)$ denote the conventionally computed expected return on equity given $R_{m}=\hat{r}_{m}$. This calculation is incorrect because it fails to revise bankruptcy risk given the actual market yield. I define conditional anomaly as the difference between full and partial information conditional expected returns, or $\mathrm{E}\left[R_{E} \mid \hat{r}_{m}\right]-\mathrm{E}\left[R_{E} \mid \hat{r}_{m}\right]^{*}$. This type of error is present when abnormal returns are used to measure the performance of an investment strategy or to test the market efficiency hypothesis in an event study.

PROPOSITION VII. Conditional anomalies depend on probability of bankruptcy, sensitivity and the observed market return $\hat{r}_{m}$ as follows:

$$
\underbrace{\mathrm{E}\left[R_{E} \mid \hat{r}_{m}\right]}_{\text {FULL INFO. }}-\underbrace{\mathrm{E}\left[R_{E} \mid \hat{r}_{m}\right]^{*}}_{\text {PARTIAL INFO. }}=\hat{k}\left(1+\mathrm{E}\left[R_{E}\right]\right)-\max \left[0,1+i+\beta_{e}^{\text {oLS }}\left(\hat{r}_{m}-i\right)\right]
$$

\section{PROPOSED ESTIMATORS FOR BETA}

In this section I propose two estimators for beta designed to address problems in the conventional OLS estimator. The first finds both $p$ and $\rho$ endogenously. The second needs an exogenous estimate of $p$.

\subsection{First Proposed Estimator: Endogenous $p$ and $\rho$}

Estimation of beta from stock returns does not fit the typical assumptions of censored or truncated regressions, which involve the estimation of parameters of an originally unconstrained distribution given a censored or truncated sample drawn from that same distribution. The problem at hand consists in estimating the parameters of a distribution of originally constrained returns. In particular, we must estimate the parameters of a truncated bivariate normal distribution given observations that exclude instances in which the lower bound was reached. Since bankruptcy risk and sensitivity are the key parameters of stock return distributions (Proposition I) and beta is a function exclusively of those two firm-specific parameters (Proposition II), the strategy is to obtain maximum-likelihood estimates of $p$ and $\rho$ from a sample of stock and market returns, which then lead to a maximum-likelihood 
estimate of beta.

Suppose we have a sample of $N$ return pairs $\left(r_{j}, m_{j}\right), j=1, \cdots N$, where $r_{j}$ and $m_{j}$ represent the $j^{\text {th }}$ realizations of $R_{E}$ and $R_{m}$ respectively. Let $\mathrm{f}^{p, \rho}\left(\cdot \mid m_{j}\right)$ be the probability density of $R_{E}$, given that $R_{m}=m_{j}$, with parameters $p$ and $\rho$. The problem is:

$$
\left\{\begin{array}{l}
\max \prod_{j=1}^{N} \mathrm{f}^{p, \rho}\left(r_{j} \mid m_{j}\right) \\
\text { with respect to } p, \rho \\
\text { subject to: } 0 \leq p<1 ;-1<\rho<1
\end{array}\right.
$$

Solutions to this problem are values of $p$ and $\rho$, denoted $p^{\prime}$ and $\rho^{\prime}$, that maximize the likelihood that this particular sample of returns was generated according to the model described in Section 2. Given the invariance property of maximum-likelihood estimators, $p^{\prime}$ and $\rho^{\prime}$ lead to a maximum-likelihood estimate of true equity beta by means of (14). To complete the specification of (29) we need an expression for $\mathrm{f}^{p, \rho}\left(r_{j} \mid m_{j}\right)$. This is given in Proposition VIII.

PROPOSITION VIII. Let $J^{*}$ be a set of firm and market return pairs $\left(r_{j}, m_{j}\right)$ that excludes observations of total losses. The probability density of $R_{E}$, given that $R_{m}=m_{j}>-100 \%$ with parameters $p$ and $\rho$ is:

$$
\mathrm{f}^{p, \rho}\left(r_{j} \mid m_{j}\right)=\frac{\mathrm{H}_{\delta \rho}^{m_{j}}}{1+i} \times \frac{\phi\left(\mu_{j}, \sigma_{j} \mid \delta+\frac{1+r_{j}}{1+i} \mathrm{H}_{\delta \rho}^{m_{j}}\right)}{\bar{\Phi}\left(\mu_{j}, \sigma_{j} \mid \delta\right)}
$$

where $\mu_{j}=\rho\left(m_{j}-\bar{r}_{m}\right) / \sigma_{m}$ and $\sigma_{j}=\sqrt{1-\rho^{2}}$.

The objective function and one of the constraints are nonlinear in $p$ and $\rho$. Once the solutions $p^{\prime}$ and $\rho^{\prime}$ are found the maximum-likelihood estimate of beta follows from Proposition II.

\subsection{Second Proposed Estimator: Exogenous $p$, Endogenous $\rho$}

The second estimator obtains OLS beta with the traditional technique, and then combines $\beta_{E}^{\text {oLS }}$ with an independent (and hopefully up-to-date) assessment of $p$, say $p^{*}$, to obtain an estimate of sensitivity $\rho^{*}$ via (24). Figure 9 illustrates how $\rho^{*}$ can be inferred from $\beta_{E}^{O L S}$ and $p^{*}$. Given $p^{*}$ and $\rho^{*}$ we estimate true beta via (14) as before. This estimator should perform well for companies that have been through significant changes in failure risk, while market sensitivity has remained relatively steady. An independent assessment of $p$ can be obtained by means of a bankruptcy prediction model such as Shumway's (2001).

The first proposed estimator for beta has the advantage of following entirely from the CAPM, but the final result is based on possibly stale historical returns (like the traditional estimator). The second proposed estimator needs input from outside the realm of the CAPM and stock returns, but in so doing allows the introduction of recent information on bankruptcy risk. 
Figure 9. Deriving sensitivity given OLS beta and probability of bankruptcy.

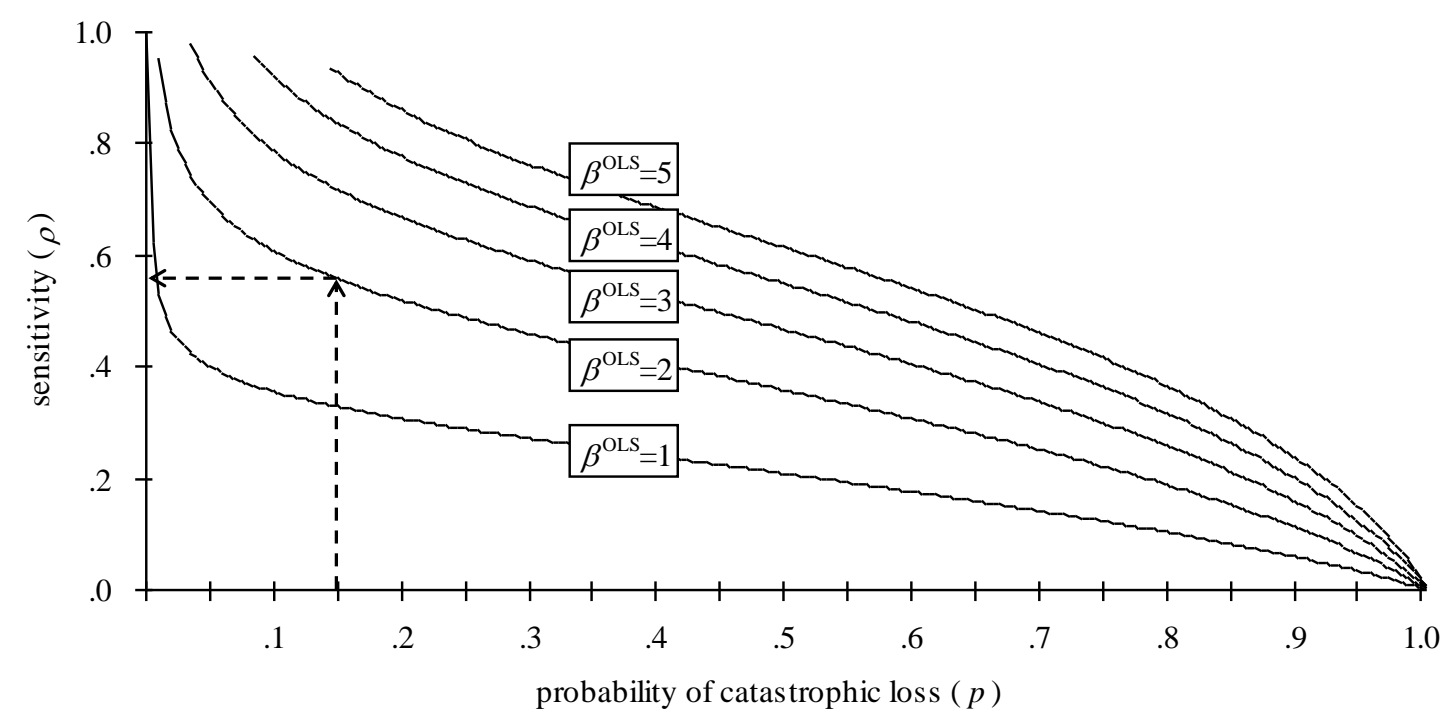

\section{CONCLUSION}

Combining the effects of diversification and of the option-to-abandon in a single valuation model suggests reasons for anomalies in models that concentrate on only one of those two factors. If total loss is possible and the likelihood of total loss is correlated with the market, then the systematic risk of equity must reflect this possibility. Even if the effect of total loss is too small to matter for most firms most of the time, it can still be sufficiently large for enough firms to generate return patterns that seem strange to those who ignore it. For instance, return patterns in which smaller firms accrue higher returns than predicted by the CAPM and in which these higher returns are associated with financial distress. Although this commentary on conventional techniques applies at any level of risk, significant practical effects are foreseen only for highly speculative investments (such as firms classified as Caa-C by Moody's).

The argument in the paper is consistent with accepted finance theory in the sense that: (1) it replicates Black and Scholes' option-equity parallel; (2) it assumes a linear relationship between expected returns and beta given the expected return on the market; and (3) it respects Modigliani and Miller's proposition on capital structure irrelevance in a tax free/costless bankruptcy economy. The paper challenges, however, the presumption that there is a linear relationship between expected returns and beta given the realized market return and the practice of estimating systematic risk via ordinary least squares.

Other results are:

- Option prices should be affected by the systematic risk of their underlying assets, in agreement with existing empirical results (Dennis and Mayhew 2002; Duan and Wei 2006).

- Expected stock returns conditional on the actual market return depend in a nonlinear fashion on the actual market return and converge to $-100 \%$ as the market return drops. This contrasts with the conventional approach in which the ex-post expected return is obtained by substituting the actual market return for the expected market return in the formula for the exante expectation (the Jensen measure).

- Two characteristics are sufficient to specify the distribution of stock returns: bankruptcy risk and market sensitivity. Bankruptcy risk subsumes the effects of leverage, size and operating risk on returns. This agrees with research that finds that the size and leverage anomalies in CAPM are subsumed by distress (CHAN; CHEN, 1991; FAMA; FRENCH, 1993; 
FAMA; FRENCH, 1996; VASSALOU; XING, 2004).

- Two firm-specific characteristics are sufficient to specify beta: bankruptcy risk and market sensitivity. Bankruptcy risk in the model is partly systematic, in agreement with findings from contingent claims based estimates of default risk (VASSALOU; XING 2004), but not with findings from accounting based estimates of default risk (DICHEV, 1998). Very distressed firms may have lower betas than very safe firms as long as high distress is accompanied by sufficiently low sensitivity levels. Hence, despite claims made elsewhere (DICHEV, 1998), the CAPM is not negated by very distressed firms yielding lower returns than very safe firms, even if this persists over long periods of time.

Allowing for risk of contagious bankruptcy has important but subtle effects on security prices. The model presented in this paper integrates aspects of the CAPM and OPM. It leads to predictions similar to those generated by traditional implementations of the Sharpe-LintnerMossin CAPM when bankruptcy risk is irrelevant, but to a different and richer set of predictions when bankruptcy risk is important.

\section{REFERENCES}

BAKSHI, G.; CAO, C.; CHEN, Z.. Empirical performance of alternative option pricing models. The Journal of Finance v. 52, n. 5, p. 2003-2049, 1998. http://dx.doi.org/10.1111/j.15406261.1997.tb02749.x

BHANDARI, L.C. Debt/equity ratio and expected common stock returns: empirical evidence. The Journal of Finance, v. 43, p. 507-528, 1988. http://dx.doi.org/10.1111/j.15406261.1988.tb03952.x

BLACK, F.; SCHOLES, M.S. The pricing of options and corporate liabilities. Journal of Political Economy, v.81, p. 637-654, 1973. http://dx.doi.org/10.1086/260062

BOWMAN, R.G. The theoretical relationship between systematic risk and financial (accounting) variables. The Journal of Finance, v.34, p. 617-630, 1979. http://dx.doi.org/10.1111/j.1540-6261.1979.tb02129.x

BODIE, Z.; KANE, A.; MARCUS, A.J. Investments. 2nd edition, Irwin, Homewood, IL, 1993.

BREALEY, R.A.; MYERS, S.C.; ALLEN, F. Principles of Corporate Finance. 8th edition, McGraw-Hill Irwin, New York, 2006.

CHAN, K.C.; CHEN, N. Structural and return characteristics of small and large firms. The Journal of Finance, v.46, n. 4, p. 1467-1484, 1991. http://dx.doi.org/10.1111/j.15406261.1991.tb04626.x

DENNIS, P.; MAYHEW, S. Risk-neutral skewness: evidence from stock options. The Journal of Financial and Quantitative Analysis, v. 37, n. 3, p. 471-493, 2002. http://dx.doi.org/10.2307/3594989

DICHEV, I.D. Is the risk of bankruptcy a systematic risk? The Journal of Finance, v. 53, p. 1131-1147, 1998. http://dx.doi.org/10.1111/0022-1082.00046

DUAN, J.; WEI, J. Is systematic risk priced in options? Rotman School of Management Working Paper No. 06-05, 2006. Available at SSRN: http://ssrn.com/abstract=902122

DYBVIG, P.H.; INGERSOLL, J.E. Mean-variance theory in complete markets. The Journal of Business, v.55, n. 2, p. 233-251, 1982. http://dx.doi.org/10.1086/296162 
FAMA, E.F.; FRENCH, K.R. Common risk factors in the returns on stocks and bonds. Journal of Financial Economics, v. 33, p. 3-56, 1993. http://dx.doi.org/10.1016/0304-405X(93)900235

FAMA, E.F.; FRENCH, K.R. Multifactor explanations of asset pricing anomalies. The Journal of Finance, v. 51, p. 55-84, 1996. http://dx.doi.org/10.1111/j.1540-6261.1996.tb05202.x

GRINBLATT, M.; TITMAN, S. A study of monthly mutual fund returns and performance evaluation techniques. The Journal of Financial and Quantitative Analysis, v. 29, n. 3, p. 419-444, 1994. http://dx.doi.org/10.2307/2331338

HALEY, C.W.; SCHALL, L.D. The Theory of Financial Decisions. McGraw-Hill, New York, 1979.

HANSON, S.D.; LADD, W. Robustness of the mean-variance model with truncated probability distributions. American Journal of Agricultural Economics, v.73, n. 2, p. 436-445, 1991. http://dx.doi.org/10.2307/1242728

HELWEGE, J.; KLEINMAN, P. Understanding aggregate default rates of high yield bonds. The Journal of Fixed Income June, 1997.

HILLEGEIST, S.A.; KEATING, E.K.; CRAM, D.P.; LUNDSTEDT, K.G. Assessing the probability of bankruptcy. Review of Accounting Studies, v.9, n. 1, p. 5-34, 2004. http://dx.doi.org/10.1023/B:RAST.0000013627.90884.b7

MANDELKER, G.N.; RHEE, S.G. The impact of the degrees of operating and financial leverage on systematic risk of common stock. The Journal of Financial and Quantitative Analysis, v. 19, p. 45-57, 1984. http://dx.doi.org/10.2307/2331000

MOODY'S INVESTORS SERVICE. Historical default rates of corporate bond issuers, 19201999. Moody's Special Comment, January, 2000.

MOSSIN, J. Theory of Financial Markets, Prentice-Hall, Englewood Cliffs, 1973.

MUTHÉN, B. Moments of the censored and truncated bivariate normal distribution. British Journal of Mathematical and Statistical Psychology, v. 43, p. 131-143, 1990. http://dx.doi.org/10.1111/j.2044-8317.1990.tb00930.x

SHUMWAY, T. The delisting bias in CRSP data. The Journal of Finance, v. 52, p. 327-340, 1997. http://dx.doi.org/10.1111/j.1540-6261.1997.tb03818.x

SHUMWAY, T. Forecasting bankruptcy more accurately: a simple hazard model. The Journal of Business, v.74, p. 101-124, 2001. http://dx.doi.org/10.1086/209665

VASSALOU, M.; XING, Y. Default risk in stock returns. The Journal of Finance. v.59, n. 2 , p. 831-868, 2004. http://dx.doi.org/10.1111/j.1540-6261.2004.00650.x 


\section{APPENDIX A \\ Proofs of Lemmas ANd Propositions}

Proof of Lemma 1:

- Expected dividends

Conditioning on the firm not being bankrupt at year-end (i.e., $X>d$ ) we can write:

$$
\mathrm{E}\left[X_{E}\right]=\mathrm{E}[\max (0, X-d)]=\mathrm{E}[\max (0, X-d) \mid X>d](1-p)
$$

This is the expectation of a normal distribution truncated below at 0 such that the unconstrained normal has mean $\mu_{X}-d$ and standard deviation $\sigma_{X}$. Therefore (MADDALA, 1983):

which is the desired result.

$$
\mathrm{E}\left[X_{E}\right]=\sigma_{X}\left[\phi_{\delta}-\delta \bar{\Phi}_{\delta}\right]=\sigma_{X} \mathrm{H}_{\delta 0}
$$

Proof of Lemma 2:

- Covariance dividends $\times$ market

Let $I$ be a random variable that takes on the value 1 if $X>d$ and 0 otherwise. The covariance between dividends and market returns can be written as:

$$
\operatorname{cov}\left(\max (X-d, 0), R_{m}\right)=\operatorname{cov}\left((X-d) I, R_{m}\right)=\operatorname{cov}\left(X I, R_{m}\right)-d \operatorname{cov}\left(I, R_{m}\right)
$$

Now make the following substitutions:

Hence:

$$
\left\{\begin{array}{l}
X=\mu_{X}+\sigma_{X} Z_{X} \\
R_{m}=\bar{r}_{m}+\sigma_{m} Z_{m}
\end{array}\right.
$$

where $Z_{X}$ and $Z_{m}$ have a bivariate standard normal distribution with correlation $\rho$, to obtain:

$$
\operatorname{cov}\left(X_{E}, R_{m}\right)=\sigma_{m}\left(\mu_{X}-d\right) \operatorname{cov}\left(I, Z_{m}\right)+\sigma_{X} \sigma_{m} \operatorname{cov}\left(Z_{X} I, Z_{m}\right)
$$

or:

$$
\operatorname{cov}\left(X_{E}, R_{m}\right)=\sigma_{m}\left(\mu_{X}-d\right) \mathrm{E}\left(I Z_{m}\right)+\sigma_{X} \sigma_{m} \mathrm{E}\left(Z_{X} I Z_{m}\right)
$$

Now the following substitutions iatroduce the basic parameters of the firm (Muthén 1990):

$$
\text { which is the desired result. } \quad \operatorname{cov}\left(X_{E}, R_{m}\right)=\rho \sigma_{X} \sigma_{m} \bar{\Phi}_{\delta}
$$$$
\left\{\begin{array}{l}
\mathrm{E}\left(I Z_{m}\right)=\rho \phi_{\delta} \\
\mathrm{E}\left(Z_{X} I Z_{m}\right)=\rho\left[1-p+\delta \phi_{\delta}\right]
\end{array}\right.
$$

Proof of Proposition I:

- Return distribution factors

Consider a state of the economy in which the realized market return and the firm's cash flows at liquidation are $R_{m}=\hat{r}_{m}$ and $X=\hat{x}$ respectively. Based on these values define:

$$
\hat{z}_{m}=\frac{\hat{r}_{m}-\bar{r}_{m}}{\sigma_{m}} \quad \hat{z}_{X}=\frac{\hat{x}-\mu_{X}}{\sigma_{X}} \quad \hat{w}=\frac{\hat{z}_{X}-\hat{z}_{m} \rho}{\sqrt{1-\rho^{2}}}
$$

$\hat{z}_{m}$ and $\hat{w}$ are realized values of independently distributed standard normals $Z_{m}$ and $W$ (Ross 1985). In order to find a minimum set of firm and market characteristics that determine the realized value of return on equity, consider parts $\mathrm{A}, \mathrm{B}$, and $\mathrm{C}$ of the expression for realized returns on equity, as follows: 


$$
\hat{r}_{E}=\underbrace{\mathrm{E}\left[X_{E}\right]}_{\text {Part B }}-\lambda \underbrace{\hat{x}_{E}(1+i)}_{\text {Part } \mathrm{C}}-1
$$

Part A: The realized dividend is given by:

$$
\hat{x}_{E}=\max (0, \hat{x}-d)=\max \left(0, \mu_{X}-d+\sigma_{X} \hat{z}_{X}\right)=\sigma_{X} \max \left(0, \delta+\hat{z}_{X}\right)
$$

Part B: The expected dividend is given in Lemma 1.

Part C: The covariance of dividends with market returns is given in Lemma 2.

Substituting parts A, B, and C into (A.10) leads to the desired result. Since $p=\Phi_{\delta}$ and $s=\left(\bar{r}_{m}-i\right) / \sigma_{m}$, it follows that the realized return on equity is a function of only two firmspecific parameters: $p$ and $(\rho)$. Other arguments are the Sharpe ratio, $i$, and pure noise $\left(Z_{X}\right)$.

Proof of Proposition II:

- True beta

Combine the definitions of $\beta_{E}$ and $R_{E}$ (expressions 4 and 8 in the manuscript) with the expression for dividends payable under limited liability ( 1 in the manuscript) to obtain:

$$
\beta_{E}=\frac{\operatorname{cov}\left(\max (X-d, 0), R_{m}\right)}{V_{E} \sigma_{m}^{2}}
$$

Use (A.8) for the numerator in (A.12) and transfer $V_{E}$ to the left hand side. Then use Lemma 1 for $\mathrm{E}\left[X_{E}\right]$ in (6). Use the two resulting valuation formulas to find the desired expression for true beta.

\section{Proof of Proposition III:}

- Equity value

The result is a direct consequence of expression (6) and Proposition II. (Note that there is a oneto-one relationship between probability of bankruptcy and $\delta$ via $p=\Phi_{\delta}$.)

\section{Proof of Lemma 3:}

- Conditional risk of bankruptcy

Let $Z_{X} \square \mathrm{N}(0,1)$ and substitute $\left(\mu_{X}+\sigma_{X} Z_{X}\right)$ for $X$ to write:

$$
\operatorname{Pr}\left[X>d \mid \hat{r}_{m}\right]=\operatorname{Pr}\left[Z_{X}>\delta \mid \hat{r}_{m}\right]
$$

$Z_{X}$ and $R_{m}$ have a joint bivariate normal distribution, and the conditional density function $\mathrm{f}\left(Z_{X} \mid \hat{r}_{m}\right)$ is distributed as $\mathrm{N}\left(\hat{\mu}_{Z}, \hat{\sigma}_{Z}\right)$, where $\hat{\mu}_{Z}=\rho\left(\hat{r}_{m}-\bar{r}_{m}\right) / \sigma_{m}$ and $\hat{\sigma}_{Z}=\sqrt{1-\rho^{2}}$ (Greene 2000). Therefore, letting $\hat{\delta}=\left(\delta-\hat{\mu}_{Z}\right) / \hat{\sigma}_{Z}$ :

$$
\operatorname{Pr}\left\{X>d \mid \hat{r}_{m}\right\}=\bar{\Phi}\left(\frac{\delta-\hat{\mu}_{Z}}{\hat{\sigma}_{Z}}\right)=\bar{\Phi}_{\hat{\delta}}
$$

Note that $\hat{\delta}$ is associated with the probability of bankruptcy given $\hat{r}_{m}$ just as $\delta$ is associated with the unconditional probability of bankruptcy.

Proof of Lemma 4: - Conditional expected cash flows

The result follows from properties of the bivariate normal distribution (Greene 2000, p. 83) and of the truncated normal distribution (Maddala 1983, p. 365). 
Proof of Lemma 5: - Ratio of conditional to unconditional expected dividends

The result is based on Lemmas $1,3,4$ and uses $\mathrm{E}\left[X_{E} \mid \hat{r}_{m}\right]=$

$$
\operatorname{Pr}\left\{X>d \mid \hat{r}_{m}\right\}\left(\mathrm{E}\left[X \mid X>d, R_{m}=\hat{r}_{m}\right]-d\right) .
$$

Proof of Proposition IV:

- Conditional expected returns

The result is based on expression (15) for the value of equity and on Lemma 5. Note that the conditioning variable $\hat{r}_{m}$ is present on the right-hand-side of (23) via $\hat{k}$, which is a function of $\hat{\delta}, \hat{z}$, and finally $\hat{r}_{m}$. It is also easy to verify that $\mathrm{E}\left[\mathrm{E}\left[R_{E} \mid \hat{r}_{m}\right]\right]=\mathrm{E}\left[R_{E}\right]=i+\beta_{E}\left(\bar{r}_{m}-i\right)$.

Proof of Proposition V:

- OLS estimator of equity beta

Beginning with the definition of beta in expression (4), impose the no-bankruptcy condition and let the random variable $I$ that equals 1 if $X>d$, and equals 0 otherwise:

$$
\beta_{E}^{o L S}=\frac{\operatorname{cov}\left(\max (X-d, 0), R_{m} \mid X>d\right)}{V_{E} \operatorname{var}\left(R_{m} \mid X>d\right)}=\frac{\operatorname{cov}\left(X, R_{m} \mid I=1\right)}{V_{E} \operatorname{var}\left(R_{m} \mid I=1\right)}
$$

Borrowing the definitions of $Z_{X}$ and $Z_{m}$ from the proof of Lemma 2 (S.4), the numerator can be expanded as follows:

$$
\operatorname{cov}\left(X, R_{m} \mid I=1\right)=\sigma_{X} \sigma_{m}\left(\mathrm{E}\left[Z_{X} Z_{m} \mid I=1\right]-\mathrm{E}\left[Z_{X} \mid I=1\right] \mathrm{E}\left[Z_{m} \mid I=1\right]\right)
$$

From Bayes' theorem and from Muthén (1990) comes:

$$
\begin{gathered}
\mathrm{E}\left(Z_{X} \mid I=1\right)=\phi_{\delta} \bar{\Phi}_{\delta}^{-1} \\
\mathrm{E}\left(Z_{m} \mid I=1\right)=\rho \phi_{\delta} \bar{\Phi}_{\delta}^{-1} \\
\mathrm{E}\left(Z_{X} Z_{m} \mid I=1\right)=\rho\left[\bar{\Phi}_{\delta}+\delta \phi_{\delta}\right] \bar{\Phi}_{\delta}^{-1} \\
\mathrm{E}\left(\left(Z_{m}\right)^{2} \mid I=1\right)=\left[\bar{\Phi}_{\delta}+\rho^{2} \delta \phi_{\delta}\right] \bar{\Phi}_{\delta}^{-1}
\end{gathered}
$$

With (A.17) through (A.20), $\operatorname{cov}\left(X, R_{m} \mid I=1\right)$ and the variance in the denominator are:

$$
\begin{gathered}
\operatorname{cov}\left(X, R_{m} \mid I=1\right)=\rho \sigma_{X} \sigma_{m} \frac{\bar{\Phi}_{\delta}^{2}+\phi_{\delta} \mathrm{H}_{\delta 0}}{\bar{\Phi}_{\delta}^{2}} \\
\operatorname{var}\left(R_{m} \mid I=1\right)=\sigma_{m}^{2}\left\{\mathrm{E}\left[\left(Z_{m}\right)^{2} \mid \tilde{I}=1\right]-\mathrm{E}\left[Z_{m} \mid I=1\right]^{2}\right\}=\sigma_{m}^{2} \frac{\bar{\Phi}_{\delta}^{2}+\rho^{2} \phi_{\delta} \mathrm{H}_{\delta 0}}{\bar{\Phi}_{\delta}{ }^{2}}
\end{gathered}
$$

Inserting (A.21) and (A.22) into (A.15), and using (15) for $V_{E}$, the desired result follows.

Proof of Proposition VI:

- Unconditional anomalies

Use (3) and the expressions for $\beta_{E}$ and $\beta_{E}^{\text {OLS }}$ in Propositions II and V. 
Follows directly from Propositions II, IV and V.

Proof of Proposition VIII:

- Maximum likelihood estimator

To determine an expression for $\mathrm{f}^{p, \rho}\left(r_{j} \mid m_{j}\right)$ I start from the fact that the cumulative distribution function of $R_{E}$, given that $R_{m}=m_{j}$ is a function $\mathrm{F}^{p, \rho}\left(r_{j} \mid m_{j}\right)$ such that $\mathrm{F}^{p, \rho}\left(r_{j} \mid m_{j}\right)=\operatorname{Pr}\left\{R_{E} \leq r_{j} \mid m_{j}\right\}$, or:

$$
\mathrm{F}^{p, \rho}\left(r_{j} \mid m_{j}\right)=\operatorname{Pr}\left\{X_{E} \leq V_{E}\left(1+r_{j}\right) \mid m_{j}\right\}=\operatorname{Pr}\left\{X \leq d+V_{E}\left(1+r_{j}\right) \mid m_{j}\right\}
$$

Setting $Z_{X}=\left(X-\mu_{X}\right) / \sigma_{X}$ and using valuation formula (15) it follows that:

$$
\mathrm{F}^{p, \rho}\left(r_{j} \mid m_{j}\right)=\operatorname{Pr}\left\{Z_{X} \leq \frac{d-\mu_{X}}{\sigma_{X}}+\frac{V_{E}\left(1+r_{j}\right)}{\sigma_{X}} \mid m_{j}\right\}=\operatorname{Pr}\left\{Z_{X} \leq \delta+\frac{1+r_{j}}{1+i} \mathrm{H}_{\delta \rho} \mid m_{j}\right\}
$$

which implies that $\mathrm{F}^{p, \rho}\left(r_{j} \mid m_{j}\right)$ is normal with mean $\mu_{j}=\frac{\rho\left(m_{j}-\bar{r}_{m}\right)}{\sigma_{m}}$ and standard deviation $\sigma_{j}=\sqrt{1-\rho^{2}}$ as defined in Lemma 3. Let $\Phi\left(\mu_{j}, \sigma_{j} \mid \square\right)$ and $\phi\left(\mu_{j}, \sigma_{j} \mid \square\right)$ represent univariate normal cumulative distribution and probability density functions with mean $\mu_{j}$ and standard deviation $\sigma_{j}$. Consider two cases: when the firm is not bankrupt $\left(r_{j}>-100 \%\right)$ and when it is ( $\left.r_{j}=-100 \%\right)$. In the first case,

$$
\mathrm{F}^{p, \rho}\left(r_{j} \mid m_{j}\right)=\Phi\left(\mu_{j}, \sigma_{j} \mid \delta+\frac{1+r_{j}}{1+i} \mathrm{H}_{\delta \rho}^{m_{j}}\right)
$$

which implies that:

$$
\mathrm{f}^{p, \rho}\left(r_{j} \mid m_{j}\right)=\frac{\mathrm{H}_{\delta \rho}^{m_{j}}}{(1+i) \bar{\Phi}\left(\mu_{j}, \sigma_{j} \mid \delta\right)} \phi\left(\mu_{j}, \sigma_{j} \mid \delta+\frac{1+r_{j}}{1+i} \mathrm{H}_{\delta \rho}^{m_{j}}\right)
$$

When the firm fails, $\mathrm{F}^{p, \rho}\left(r_{j} \mid m_{j}\right)$ is defined as:

$$
\mathrm{F}^{p, \rho}\left(-100 \% \mid m_{j}\right)=\bar{\Phi}\left(\mu_{j}, \sigma_{j} \mid \delta\right)
$$

which is the conditional probability of bankruptcy given that the return on the market portfolio is $m_{j}$. The probability density function is not defined in this case.

Let $J^{*}$ be the set of firm and market return pairs $\left(r_{j}, m_{j}\right)$ such that bankruptcy does not occur. Using (S.26) the maximization problem can be written as:

$$
\max \prod_{j \in J^{*}} \frac{\mathrm{H}_{\delta \rho}^{m_{j}}}{(1+i) \bar{\Phi}\left(\mu_{j}, \sigma_{j} \mid \delta\right)} \phi\left(\mu_{j}, \sigma_{j} \mid \delta+\frac{1+r_{j}}{1+i} \mathrm{H}_{\delta \rho}^{m_{j}}\right)
$$


APPENDIX B

SAS PROCEDURE TO OBTAIN MAXIMUM LIKELIHOOD ESTIMATES OF BANKRUPTCY RISK

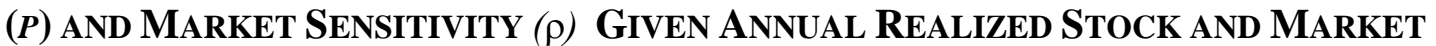
RETURNS

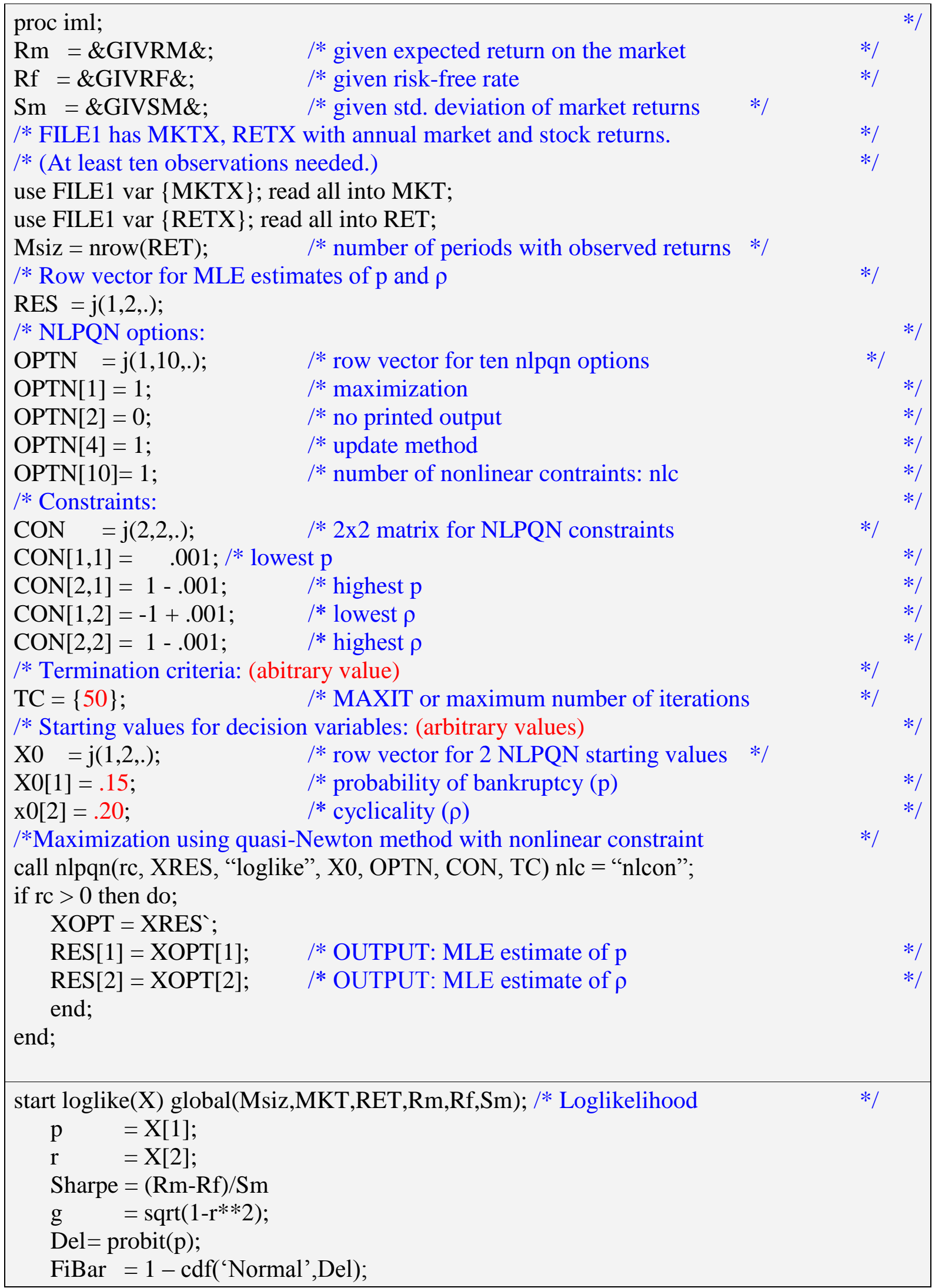




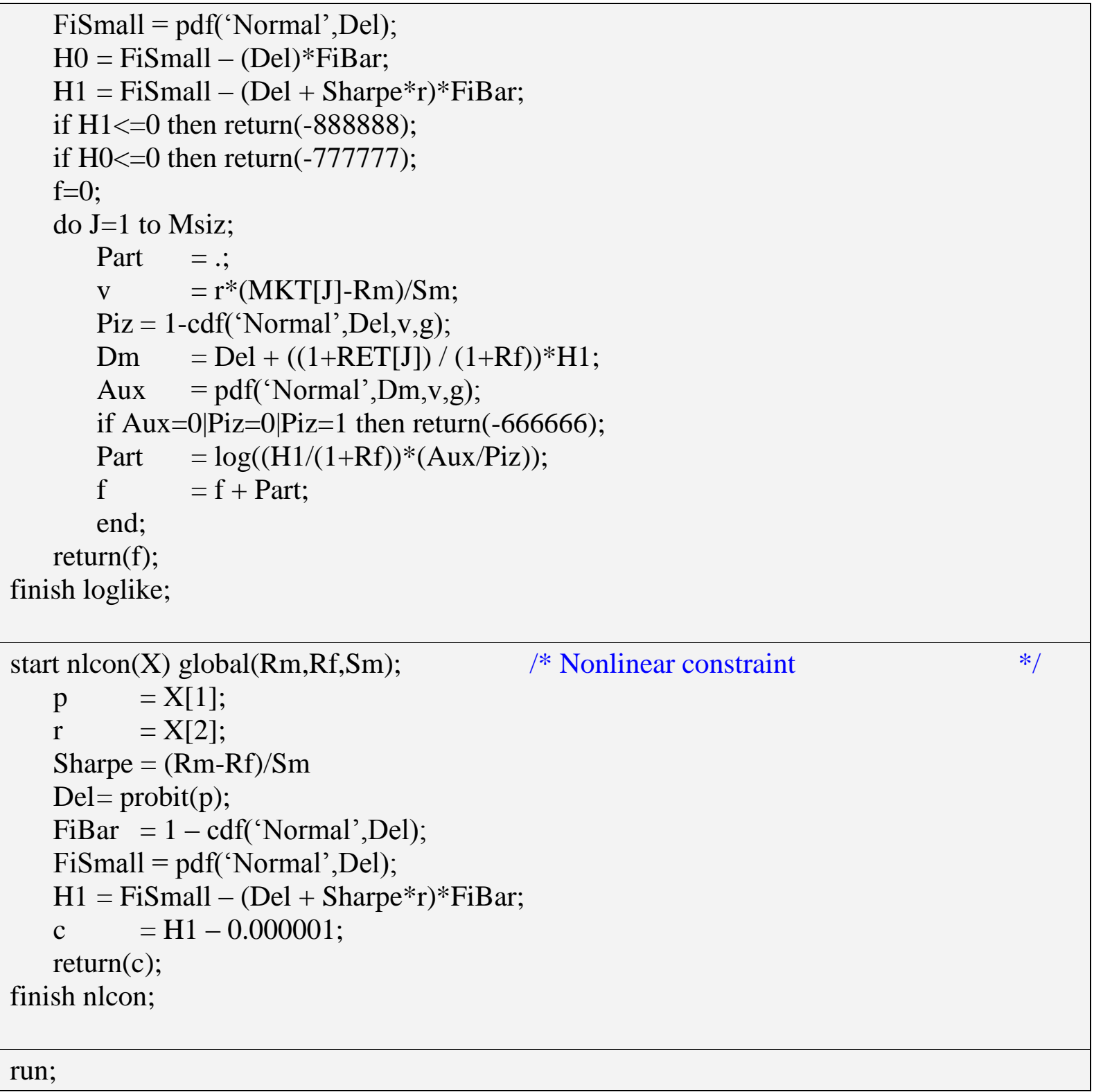




\section{APPENDIX C \\ Does a CENTRAL Limit TheOREM Hold?}

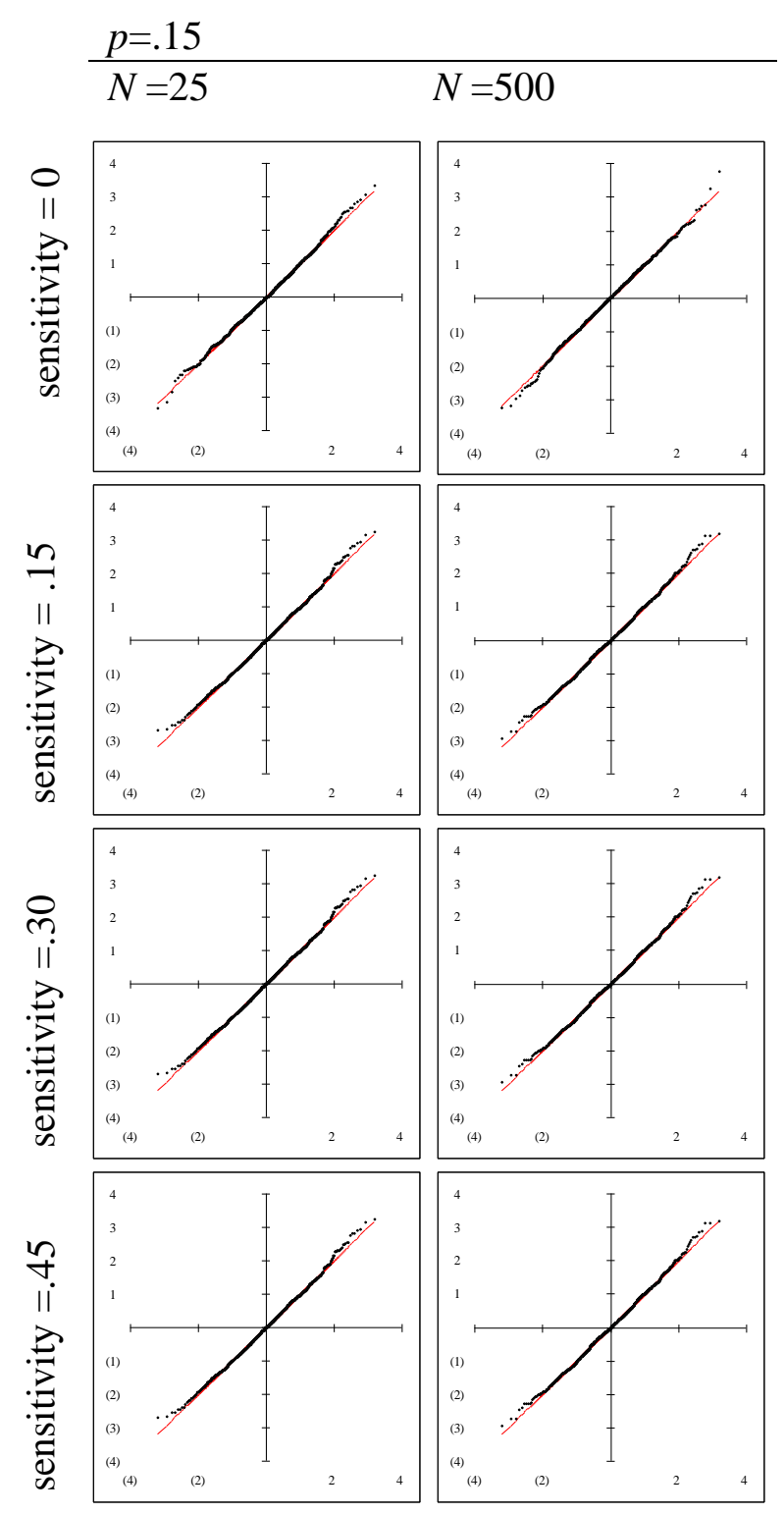

$\frac{p=.75}{N=25} \quad N=500$
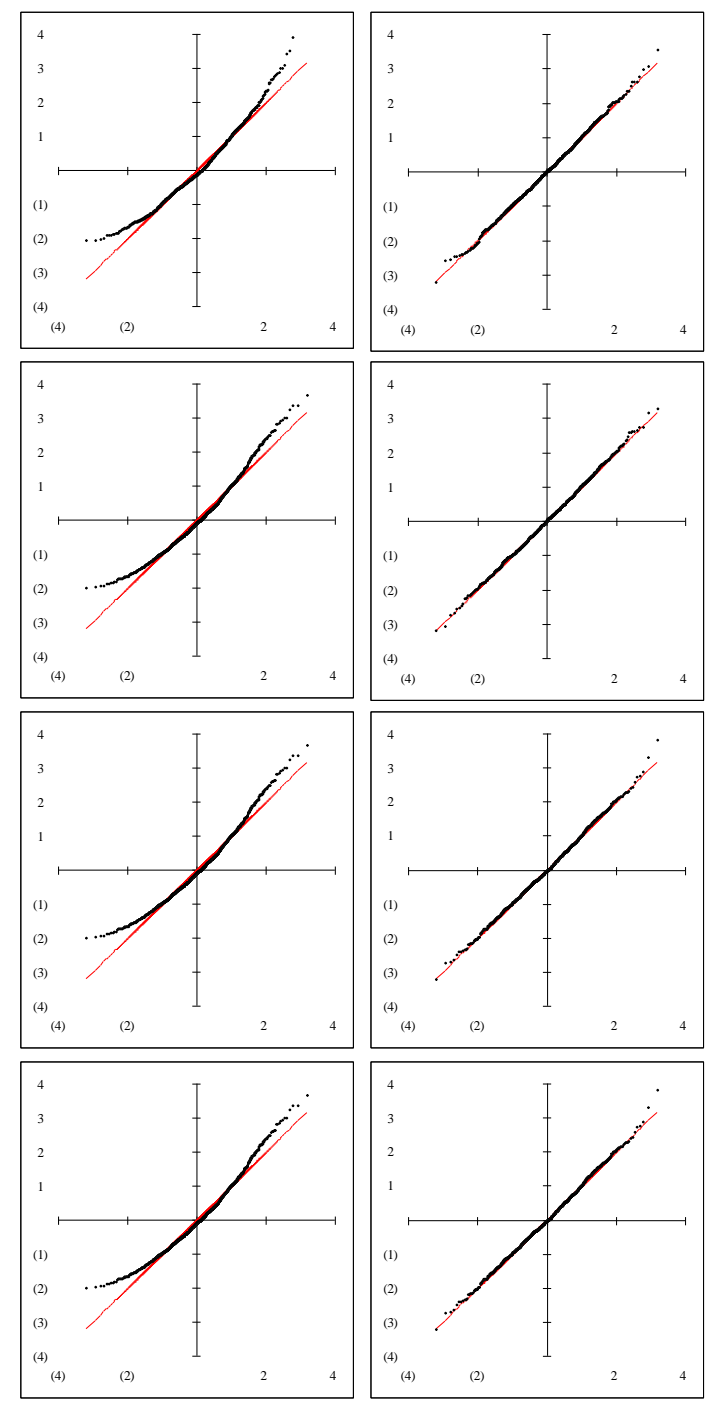

Exhibit C.1. Probability plots to test visually for normality. Portfolios with $N=25$ and $N=500$ securities at selected levels of sensitivity $(\rho)$ and bankruptcy risk $(p)$

Discussion: The return on the market portfolio $\left(R_{m}\right)$ is a value-weighted average of returns on securities. If those returns are independent and identically distributed then by the central limit theorem $R_{m}$ approaches normality as $N$ (number of securities) $\rightarrow \infty$. But stock returns in this paper follow diverse and interdependent truncated normal distributions. Thus, the sufficient conditions for the Lindeberg-Lévy and Lapunov central limit theorems fail (CONOVER, 1980). In order to check if normality of $R_{m}$ is consistent with the model of Section 2, I built simulated portfolios of securities (all securities with the same $p$ and $\rho$ parameters) and tested whether the distribution of this " $R_{m}$ " could be distinguished from normal. Exhibit C.1 shows probability plots for selected $p$ and $\rho$ values for $N=25$ and 500. Exhibit C. 2 has the corresponding skewness ratios, kurtosis ratios and Ryan-Joiner statistics. At extreme levels of bankruptcy risk ( $p=.75$ !) for ALL securities the hypothesis that " $R_{m}$ " is normally distributed is rejected when 
$N=25$ but not when $N=500$ at the usual significance levels. There is a clear trend toward normality as $N$ grows.

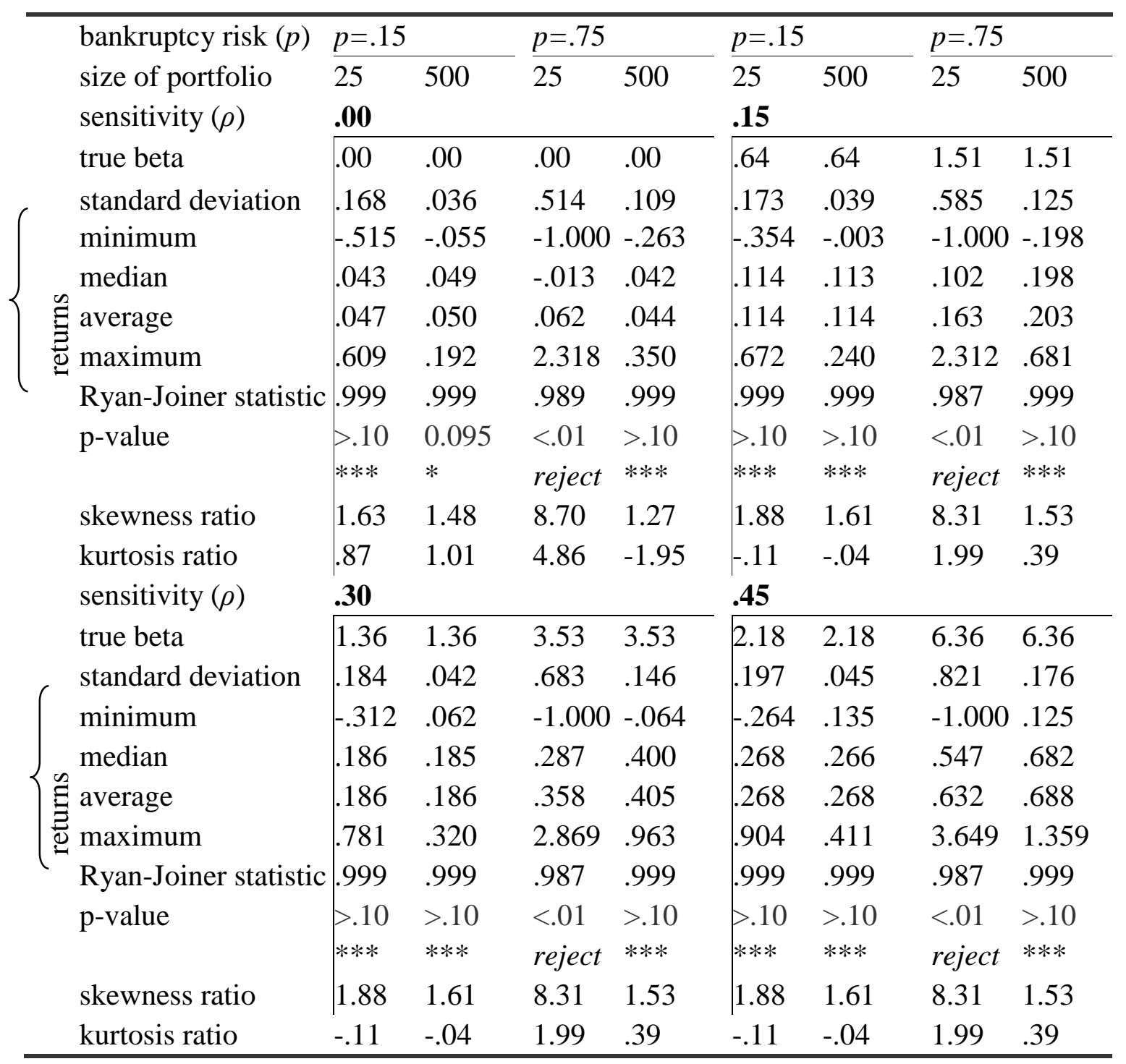

Exhibit C.2. Test of normality results based on simulated returns of portfolios with $N=25$ and $N=500$ securities at selected levels of sensitivity $(\rho)$ and bankruptcy risk $(p)$.

\section{REFERENCES}

CONOVER, W.J. Practical Nonparametric Statistics. $2^{\text {nd }}$ Edition, John Wiley \& Sons, New York, 1980.

GREENE, W.H. Econometric Analysis. $4^{\text {th }}$ edition. Prentice Hall International, 2000.

MADDALA, G.S. Limited-Dependent and Qualitative Variables in Econometrics. Cambridge University Press, Cambridge, 1983. http://dx.doi.org/10.1017/CBO9780511810176 MUTHÉN, B. Moments of the censored and truncated bivariate normal distribution. British Journal of Mathematical and Statistical Psychology, v. 43, p. 131-143, 1990. http://dx.doi.org/10.1111/j.2044-8317.1990.tb00930.x

ROSS, S.M. Introduction to Probability Models. $3^{\text {rd }}$ edition, Academic Press, Orlando, 1985. 
1 With quadratic preferences mean-variance analysis is admissible under truncated returns (DYBVIG; INGERSOLL, 1982) The quadratic form is problematic because it implies satiation and increasing absolute risk aversion. An alternative is to rely on results that show that mean-variance is robust under truncated returns, regardless of the shape assumed for investors' utility function (HANSON; LADD, 1991).

2 Simulations show that as the number of securities increases, even if all are subject to high risk of failure, returns on the portfolio tend to normal. (Available from author.) Thus normally distributed market returns are not inconsistent with firm-specific returns being truncated normal.

${ }^{3}$ When the value of the underlying asset changes due to changes in expected cash flows the volatility of returns also changes. In the two experiments above the true volatility is used in the OPM formula, even though the OPM assumes that volatility is invariant with respect to $V_{A}$. This is consistent with research on alternative option pricing models (BAKSHI; CAO; CHEN, 1997)

${ }^{4}$ The conditioning variable $\hat{r}_{m}$ appears on the right hand side of expression (23)—as it must—because it is included in the definition of $\hat{\mu}_{z}$ (Lemma 3$)$, which in turn affects $\hat{\delta}$, which is part of $\hat{k}$. 